\title{
Comprehensive Soot Particle Size Distribution Modelling of a Model Rich-Quench-Lean Burner
}

\author{
Savvas Gkantonas ${ }^{\mathrm{a}, *}$, Mariano Sirignano ${ }^{\mathrm{b}}$, Andrea Giusti $^{\mathrm{c}}$, Andrea D'Anna $^{\mathrm{b}}$, \\ Epaminondas Mastorakos ${ }^{\mathrm{a}}$ \\ ${ }^{a}$ Department of Engineering, University of Cambridge, Cambridge, UK \\ ${ }^{b}$ Dipartimento di Ingegneria Chimica, dei Materiali e della Produzione Industriale, \\ Università degli Studi di Napoli Federico II, Napoli, Italy \\ ${ }^{c}$ Department of Mechanical Engineering, Imperial College London, London, UK
}

\begin{abstract}
Soot particle size distribution (PSD) evolution in an ethylene lab-scale swirl Rich-Quench-Lean (RQL) combustor is investigated using a detailed physicochemical sectional soot model coupled with the Conditional Moment Closure turbulent combustion model and Large Eddy Simulation. The aim is to develop predictive capability for the local soot PSD and to explore differences in soot PSDs with different conditions of a burner configuration widely used in practice for emissions control. Two such conditions are studied by varying the airflow provided in the burner primary and dilution regions, which has a drastic effect on soot emission as shown by previous experiments. The results show a reasonably good agreement with experiments for the mean reaction zone and soot locations and their variations with dilution. The predicted PSDs at the burner exit are fairly well captured for the high-dilution condition but show too few and too small particles for the dilution-free condition, which may be due to an overprediction of the oxidation rates or the unity Lewis number assumption used here that enhances penetration of soot towards the oxidiser stream. The results are analysed to reveal the hierarchy of reaction pathways during soot evolution and indicate how dilution air modifies the soot PSD within the primary zone. In particular, the presence of dilution leads to a broadly sustained uni-modal soot
\end{abstract}

\footnotetext{
${ }^{*}$ Corresponding author

Email address: sg834@cam.ac.uk (Savvas Gkantonas)
}

Preprint submitted to Fuel

February 20, 2020 
PSD shape and a decrease in particle size. The results demonstrate a framework for capturing soot PSD in realistic combustion devices, which may help meet future regulations based on particle number and size distribution.

Keywords: Soot Modelling, Particle size distribution, Rich-Quench-Lean, Conditional Moment Closure, Large Eddy Simulation, Sectional model

\section{Introduction}

The prediction of soot emissions from practical combustion devices is of crucial importance if next-generation low-emission aero-engines are to mitigate the deleterious effects of particulate matter to human health and the environ-

5 ment 1]. Due to the kinetically-controlled nature of soot evolution and its high sensitivity to flame thermo-chemical composition history, soot modelling in turbulent flames necessitates accurate knowledge of the mixing field at the large and small scale [2], the relevant pathways to soot formation and oxidation [3], but also the morphology of soot particles [4. Theories for the distribution of size and shape of soot particles are not only required for accurate predictions, but also for new regulations which impose limitations on the particle number [5]. This paper presents a step in this direction for flames in geometrical configurations of high relevance to aviation combustors.

Many experimental and numerical studies have focused on the characterisation of soot emissions in simplified laminar (e.g., 6, 7]) and turbulent (e.g., [8, 9, 10]) configurations with gaseous fuels that now constitute targets of the International Sooting Flame (ISF) workshop. Although useful, the flow dynamics and their associated time-scales are not the same as in aeronautical gas turbine combustors [11, the majority of which are based on the Rich-Quench-Lean 20 (RQL) concept, i.e., fuel-rich combustion followed by intense mixing and dilution with air. An ethylene swirl flame at elevated pressure [12, 13] has been developed with this in mind. A variety of combustion models ranging from tabulated [14, 15, 16, 17, 18, 19, to quasi-laminar chemistry (i.e., neglecting sub-grid scale fluctuations) [20, 21] have been used to simulate this burner. 
Each approach has strengths and weaknesses, but it is commonly accepted that to capture soot emission accurately, transport and chemistry have to be solved simultaneously [5]. This becomes necessary when complex flow patterns, as in RQL-type configurations, are to be analysed.

In addition, soot models used in these studies relied either on semi-empirical 30 or moment-based methods that may not provide enough information on the soot particle size distribution (PSD). Methods able to replicate the soot PSD in turbulent flames have only been studied recently [22, 23, 24] and have only been tested in turbulent jet non-premixed flames. Therefore, there is a need to explore soot evolution in RQL-like conditions using a comprehensive modelling strategy able to reproduce multi-scale turbulence-soot PSD interactions and to properly account for history and finite-rate chemistry effects. Apart from access to the soot PSD and more accurate predictions, simulations combining state-of-the-art turbulent combustion and soot modelling approaches can provide useful physical insights into the underlying soot evolution phenomena and aid the aero-engine 40 design process. This paper focuses on the evolution of soot PSDs in a richburn recirculating flame with addition of dilution air, typical of aviation RQL combustors. This is a configuration significantly different than the canonical jet flame from the perspective of mixing patterns, residence times, and strain rates, hence it deserves special attention.

45 Herein, Large Eddy Simulation (LES) with the Conditional Moment Closure (CMC) combustion model is used to simulate an ethylene lab-scale burner that has been developed at the University of Cambridge and replicates the major features of the RQL concept [25, 26, 27], similar to the DLR burner [12, 13], but with different air-fuel injection systems (axial vs angled annular) and extra degrees of freedom (variable dilution jet location, range of dilution ratios, spray capability). In particular, this work evaluates the reasons why dilution air drastically reduces the overall soot emission in the Cambridge RQL burner, as shown by measurements of soot volume fraction [26, 27, 28] and PSDs inflame [28] and at the exhaust [25, 28]. The experiments reveal that this device is characterised by high soot production in the primary zone and strong oxidation 
due to dilution. The soot PSD at the exhaust results from the balance of these two strong phenomena, which is generally very challenging to simulate, especially when rapid mixing and strong scalar dissipation rate (SDR) effects are present.

The LES-CMC approach is based on the time-resolved solution of the local flame structure in mixture fraction space and incorporates molecular mixing and turbulent transport. This allows for a more elaborate description of the unsteady reacting field and to explicitly account for SDR and residence time effects that are known to have a zeroth-order effect on soot evolution [29]. In its current formulation, LES-CMC has already shown a capability to capture soot emissions at engine-relevant conditions [30] and has been used in investigations of the Cambridge RQL burner using a semi-empirical two-equation soot model [31]. These studies marked the soot tendency changes with modifications to airflow conditions and demonstrated that LES-CMC is a promising framework for capturing soot emissions. However, the simplified soot chemistry and the mono-disperse soot formulation employed in the past have limited the scope of the analysis; thereby this paper also aims to extend it by focusing on the evolution of soot PSDs with a detailed kinetic mechanism of aromatic growth, particulate formation and oxidation, employing a sectional method for 75 the particle phase.

The paper is structured as follows. The modelling approach used in the simulations is first introduced, also containing a summary of the soot modelling specifics. This is followed by a description of the investigated burner and the numerical setup. Next, the flow and flame characteristics are discussed, and soot volume fraction predictions are reported. An analysis of the simulated soot PSDs is then conducted, followed by a discussion on the flame structure in mixture fraction space and the hierarchy of soot evolution pathways within this combustor. Conclusions and recommendations for future work close the paper. 


\section{Method and configuration}

85

\subsection{LES and CMC modelling}

Simulations were performed at the University of Cambridge using the LES approach and the CMC combustion model. The Favre-filtered continuity and momentum equations, as well as transport equations for the mixture fraction, $\widetilde{\xi}$, and its sub-grid scale variance, $\widetilde{\xi^{\prime \prime 2}}$, are solved using the unstructured finite with the Vreman model [33, allowing for a vanishing sub-grid scale turbulent viscosity at the wall. The singly-conditioned CMC formulation adopted here is based on the solution of species and enthalpy conditioned on the mixture fraction, which are solved using an in-house unstructured code [34, 35, 36. The and coupling between the solvers is achieved through density and temperature. Unconditional quantities are calculated from the CMC solution through integration over the mixture fraction Filtered probability Density Function (FDF). Before the transfer to the LES level, an inverse square distance interpolation method, based on all neighbour CMC cells, is applied to the CMC solution. $\tilde{P}(\eta)$ is modelled with a presumed $\beta$-function computed from $\widetilde{\xi}$ and $\widetilde{\xi^{\prime \prime 2}}$, which is replaced by a delta function in the case of singularities.

The CMC equation for a conditionally filtered mass fraction of a generic gas-phase species or a lumped species (bin) of the soot model, $Q_{\alpha} \equiv \widetilde{Y_{\alpha}} \mid \eta$, can be written in the following form:

$$
\begin{aligned}
& \underbrace{\frac{\partial Q_{\alpha}}{\partial t}}_{\text {T0-unsteady }}+\underbrace{\frac{\partial\left(\widetilde{u_{i} \mid \eta} Q_{\alpha}\right)}{\partial x_{i}}}_{\text {T1-convection }}=\underbrace{Q_{\alpha} \frac{\partial \widetilde{u_{i} \mid \eta}}{\partial x_{i}}}_{\text {T2-dilatation }}+\underbrace{e_{\alpha}}_{\text {T3-sub-grid scale }} \\
& +\underbrace{\widetilde{N \mid \eta} \frac{\partial^{2} Q_{\alpha}}{\partial \eta^{2}}}+\underbrace{\widetilde{\omega_{\alpha} \mid \eta}} \\
& \text { T4-micro-mixing T5-chemistry }
\end{aligned}
$$

where $\eta$ is the mixture fraction sample space variable, and $\widetilde{u_{i} \mid \eta}, \widetilde{N \mid \eta}, \widetilde{\omega_{\alpha} \mid \eta}$ are the filtered conditional velocity, scalar dissipation rate (SDR) and chemical 
source term, respectively. The sub-grid scale contribution, $e_{\alpha}$, is closed with a gradient assumption [34, whereas the filtered conditional velocity is modelled as $\widetilde{u_{i} \mid \eta}=\widetilde{u_{i}}$. The conditional SDR is obtained through a FDF-weighted integration over each CMC cell (which contains a number of LES cells) by first applying the Amplitude Mapping Closure (AMC) model [37] at the LES mesh, i.e., $\widetilde{N \mid}^{L E S}=N_{0} G(\eta)$ where $G(\eta)$ and $N_{0}$ are $G(\eta)=\exp \left(-2\left[\operatorname{erf}^{-1}(2 \eta-1)\right]^{2}\right)$ and $N_{0}=\tilde{N} / \int_{0}^{1} \tilde{P}(\eta) G(\eta) d \eta$, respectively. The filtered scalar dissipation rate, $115 \tilde{N}$, is computed considering both the resolved and sub-grid scale contributions, i.e., $\tilde{N}=\tilde{N}_{\text {res }}+\tilde{N}_{s g s}$ in which $\tilde{N}_{\text {res }}=D \nabla \tilde{\xi} \cdot \nabla \tilde{\xi}$ and $\tilde{N}_{s g s}=\frac{C_{N}}{2} \frac{\mu_{t}}{\bar{\rho} \Delta^{2}} \widetilde{\xi^{\prime \prime 2}}$ with $C_{N}=42$ [38]. $D$ is the molecular diffusivity $(D=\mu /(\bar{\rho} S c)$ with $S c=0.7), \mu_{t}$ the sub-grid scale viscosity, $\bar{\rho}$ the filtered density and $\Delta$ the filter width, estimated as the cube root of the LES cell volume.

In view of the absence of a thoroughly established model for differential diffusion in the LES-CMC framework and in view of the aim of this work to perform a first analysis of a swirl flame with a complex soot model, differential diffusion effects are neglected here. Differential diffusion in LES-CMC for non-premixed flames has only been attempted once by Navarro-Martinez and Rigopoulos [39]. Their method has only been tested in a jet flame with reasonable prediction of the soot volume fraction when assuming negligible differential diffusion transport at the small scale [39]. However, the contribution of the latter compared to large scale transport in conditional space is not well understood, and the approach in Ref. 39] may not be appropriate for any flame conditions. Therefore, the development of comprehensive models for differential diffusion effects, as well as their quantification in the Cambridge RQL combustor, should be the subject of further investigations. In this direction, available models developed for RANS-CMC can be adopted to close sub-grid scale differential diffusion terms. There are two major categories of models either relying on the solution of additional transport equations [40, 41] or a rearrangement of the diffusion term that requires the use of a mixture fraction based only on the gaseous mixture [42, 43, 44]. A priori or a posteriori assessments of these models in the context of LES-CMC may elucidate the contributions of 
small scale differential diffusion transport and complement existing DNS findings on jet flames [29, 45, 46, 47]. The neglect of the high Lewis (Schmidt) number of particles might result in some errors, but these may not be very large in the investigated flames. This will be discussed later when analysing various conditional distributions in mixture fraction space compared to a laminar flame solution, where the gaseous and particle phases have different diffusivities. Thermophoretic forces have also been neglected based on the findings of previous DNS studies [45, 47].

The chemical source term $\widetilde{\omega_{\alpha} \mid \eta}$ is closed with a first-order approximation. A similar equation is solved for the enthalpy with the conditional chemical source term being replaced by a conditional heat loss term $\widetilde{\omega_{h} \mid \eta}$. Here, an opticallythin approximation is employed to account for the radiation losses emitted by soot particles, water vapour, $\mathrm{CO}_{2}, \mathrm{CO}$ and $\mathrm{CH}_{4}$, which has been proven a satisfactory approximation for the conditions studied herein [48]. Radiation from the gaseous-phase species is based on the RADCAL model with radiation properties taken from the online TNF workshop database (http://www . sandia. gov/TNF/radiation.html). As far as soot particles are concerned, soot particle mean absorptivity $K_{a}$ is assumed to vary according to $K_{a}=\left(C \cdot f_{v}\right) / \lambda$, with $f_{v}$ the total soot volume fraction, $\lambda$ the wavelength and $C$ a dimensionless constant taken equal to 10 [49]. Following Hall [50], after the integration over all solid angles and wavelengths, $\widetilde{\omega_{h} \mid \eta}$ reads:

$$
\widetilde{\omega_{h} \mid \eta}=-\underbrace{\sum_{i} \frac{4 \sigma_{o} a_{p, i} p Q_{i} W}{i}\left(\widetilde{T \mid \eta}^{4}-T_{b}^{4}\right)}_{\text {gas: } \mathrm{i}=\mathrm{H}_{2} \mathrm{O}, \mathrm{CO}_{2}, \mathrm{CO}, \mathrm{CH}_{4}}-\underbrace{19.28 \cdot 10^{-6} \pi C \frac{\widetilde{\rho \mid \eta} Q_{s}}{\rho_{s}}\left(\widetilde{T \mid \eta}^{5}-T_{b}^{5}\right)}_{\text {soot particles }}
$$

160 assumed equal to $298 K$ and $W$ the molecular mass of the mixture and $\rho_{s}$ the soot particle density taken equal to $1800 \mathrm{~kg} / \mathrm{m}^{3} . Q_{s}=Y_{s} \mid \eta$ stands for the conditional total soot mass fraction, whereas $W_{i}$ and $a_{p, i}$ are the molecular mass and Planck absorption coefficient of species $i$. 


\subsection{Gas-phase mechanism and soot model}

The soot model used here relies on a detailed physicochemical model which has been developed and extensively tested by D'Anna and co-workers [51, 52, 53 , [54, 55]. This model has been demonstrated to successfully predict soot formation for various fuels [56, 57] and flame configurations [58, 59] whilst supporting the latest experimental evidence of soot evolution in laminar flames $[1,3,60,61$, 62. The detailed gas-phase mechanism included pyrolysis/oxidation of hydrocarbons and considered the sequential addition of acetylene molecules and the self-combination of resonantly stabilised radicals to account for the molecular growth of aromatic cycles up to pyrene. All species with greater molecular mass the soot model.

The most recent version of this model employed a multi-sectional approach which simultaneously tracks several properties of the lumped species such as their type, size, state and hydrogen content [54, 55]. Reactions for the lumped species and the gaseous-phase species involved in the soot model were treated as elementary reactions in accordance with the sectional approach. Stoichiometric coefficients were calculated following Pope and Howard 63 by assuming an intra-bin distribution uniform in mass. Rate constants, $k$, were based on a modified Arrhenius expression which also includes a dependency on the carbon number, $n_{C}$, and the hydrogen to carbon atoms ratio, $\mathrm{H} / \mathrm{C}$, of the lumped species. A detailed description and a complete list of reactions are given in Ref. [54].

A simplification of the above multi-sectional model is used here to reduce the computational requirements since this work focuses on turbulent flames and online solution of the chemistry through CMC. Particle size distribution is defined by a single range of sections (bins), each containing a nominal hydrocarbon species in order of increasing atomic mass. The carbon number ranges from 24 to about $1 \times 10^{10}$, which is equivalent to a mean mass diameter, $D_{m m}$, range of $0.8-630 \mathrm{~nm}$ assuming a constant soot particle density, $\rho_{s}$, hence covering a 
two sections are used in a geometric series with a carbon number ratio of, at least, two between sections. For each carbon number $n_{C}$, a stable (BIN) and a radical form $\left(\mathrm{BIN}^{*}\right)$, i.e., a stable lumped species missing one H-atom, is used so that particles are classified both by their size and state. Other properties, such as hydrogen content, have been extracted from the original version of the model and are directly considered in the formulation of kinetic rates. Various properties for the stable lumped species are given in Table 1

Similar to the original approach, physical and chemical pathways affecting soot evolution are included in the particle phase scheme, and reactions are based on a modified Arrhenius expression with an additional dependency on the carbon number. For a section $j$ of state $s, \mathrm{BIN}_{j}^{s}$, the term T5 of Eq. 1 reads:

$$
\begin{aligned}
& \widetilde{\omega_{B I N_{j}^{s}}} \mid \eta=\underbrace{\widetilde{\Omega_{\text {nuc }}^{j, s} \mid \eta}}_{\text {nucleation }}+\underbrace{\widetilde{\Omega_{g \text { grow }}^{j, s}} \mid \eta}_{\mathrm{C}_{2} \mathrm{H}_{2} \text { surface growth }}+\underset{\text { PAH condensation }}{\widetilde{\Omega_{\text {cond }}^{j, s}} \mid \eta}+\underbrace{\widetilde{\Omega_{\text {coag }}^{j, s} \mid \eta}}_{\text {coagulation }} \\
& +\underbrace{\widetilde{\Omega_{o x}^{j, s} \mid \eta}}_{\text {oxidation via } \mathrm{OH} / \mathrm{O}_{2}}+\underbrace{\widetilde{\Omega_{\text {frag }}^{\tilde{j, s}} \mid \eta}}_{\mathrm{O}_{2} \text {-induced fragmentation }}+\underbrace{\widetilde{\Omega_{c h r}^{j, s} \mid \eta}}_{\text {reactivity changes }}
\end{aligned}
$$

where subscripts correspond to grouped reactions presented in Table 2. Here, $\mathrm{A}_{i}$ is an aromatic compound, i.e., a Polycyclic Aromatic Hydrocarbon (PAH), among naphthalene $\left(A_{2}\right)$, acenaphthylene $\left(A_{2} R_{5}\right)$, phenanthrene $\left(A_{3}\right)$ or pyrene $\left(\mathrm{A}_{4}\right)$ and $\mathrm{R}_{i}$ its available radicals in the gas-phase mechanism. For the lumped species, the thermochemical properties of pyrene are considered [54. Overall, the lumped species mechanism contains 1763 reactions and 44 bins, whereas the gas-phase mechanism consists of 243 reactions and 67 species, and can be found in the Supplemental Materials of this article.

To demonstrate the changes associated with the reduced approach, the new soot model has been tested for the non-premixed, co-flowing, non-smoking, ethylene/air flame of Santoro and co-workers [6, 64, a well-characterised laminar sooting flame and target of the ISF workshop (referred to as the Santoro flame hereafter). The simulation was performed at the University of Naples Federico 220 II using an in-house solver for laminar flames that considers differential diffu- 
Table 1: Particle classes and properties of stable lumped species considered in this work, i.e., number of carbons $\left(n_{C}\right), H / C$ ratio, median mass and mean mass diameter $\left(D_{m m}\right)$.

\begin{tabular}{lcccc}
\hline BIN $_{i}$ & $n_{C}$ & $H / C$ & Median mass $(\mathrm{amu})$ & $D_{m m}(\mathrm{~nm})$ \\
\hline \multicolumn{2}{l}{ Nanoparticles } & & & \\
$i=1$ & 24 & 0.792 & 307 & 0.82 \\
2 & 48 & 0.688 & 609 & 1.02 \\
3 & 96 & 0.604 & 1212 & 1.29 \\
4 & 192 & 0.526 & 2408 & 1.62 \\
5 & 384 & 0.458 & 4790 & 2.04 \\
6 & 768 & 0.400 & 9534 & 2.56 \\
7 & 1610 & 0.345 & $1.99 \times 10^{4}$ & 3.27 \\
8 & 3555 & 0.295 & $4.37 \times 10^{4}$ & 4.25 \\
9 & 8160 & 0.249 & $1.00 \times 10^{5}$ & 5.61 \\
Primary & and mature & particles & & \\
10 & $1.96 \times 10^{4}$ & 0.209 & $2.94 \times 10^{5}$ & 7.50 \\
11 & $4.90 \times 10^{4}$ & 0.174 & $5.97 \times 10^{5}$ & 10.17 \\
12 & $1.27 \times 10^{5}$ & 0.144 & $1.55 \times 10^{6}$ & 13.97 \\
13 & $3.44 \times 10^{5}$ & 0.118 & $4.17 \times 10^{6}$ & 19.44 \\
14 & $9.62 \times 10^{5}$ & 0.096 & $1.17 \times 10^{7}$ & 27.38 \\
15 & $2.79 \times 10^{6}$ & 0.078 & $3.37 \times 10^{7}$ & 39.03 \\
16 & $8.37 \times 10^{6}$ & 0.062 & $1.01 \times 10^{8}$ & 56.27 \\
17 & $2.60 \times 10^{7}$ & 0.050 & $3.13 \times 10^{8}$ & 82.01 \\
18 & $8.31 \times 10^{7}$ & 0.039 & $1.00 \times 10^{9}$ & 120.82 \\
19 & $2.74 \times 10^{8}$ & 0.031 & $3.30 \times 10^{9}$ & 179.84 \\
20 & $9.32 \times 10^{8}$ & 0.024 & $1.12 \times 10^{10}$ & 270.64 \\
21 & $3.26 \times 10^{9}$ & 0.019 & $3.92 \times 10^{10}$ & 410.43 \\
22 & $1.17 \times 10^{10}$ & 0.015 & $1.41 \times 10^{11}$ & 628.96 \\
\hline & & & &
\end{tabular}


Table 2: Lumped species mechanism.

\begin{tabular}{|c|c|c|c|c|c|c|}
\hline \multirow[t]{2}{*}{ Classes } & \multirow[t]{2}{*}{ Reactions } & \multicolumn{3}{|c|}{$k=A T^{n} \exp (-E / R T)\left(m \cdot n_{C}\right)^{p}$} & \multirow[b]{2}{*}{$m$} & \multirow[b]{2}{*}{$p$} \\
\hline & & $A$ & $n$ & $E$ & & \\
\hline \multicolumn{7}{|c|}{ 1. Particle inception (nucleation) } \\
\hline nuc & $\mathrm{A}_{i}+\mathrm{A}_{i} \rightarrow$ products & $8.00 \times 10^{12} \times \gamma_{1}$ & 0.5 & 0 & 1 & $1 / 6$ \\
\hline nuc & $\mathrm{R}_{i}+\mathrm{R}_{i} \rightarrow$ products & $8.00 \times 10^{12} \times \gamma_{1}$ & 0.5 & 0 & 1 & $1 / 6$ \\
\hline nuc & $\mathrm{A}_{i}+\mathrm{R}_{i} \rightarrow$ products & $8.00 \times 10^{12} \times \gamma_{1}$ & 0.5 & 0 & 1 & $1 / 6$ \\
\hline \multicolumn{7}{|c|}{ 2. Dehydrogenation and H-atom loss } \\
\hline $\operatorname{chr}$ & $\mathrm{BIN} \rightarrow \mathrm{BIN}^{*}+\mathrm{H}$ & $6.00 \times 10^{14}$ & 0 & 113,100 & 1 & 0.8 \\
\hline $\operatorname{chr}$ & $\mathrm{BIN}^{*}+\mathrm{H} \rightarrow \mathrm{BIN}$ & $7.83 \times 10^{13}$ & 0 & 16,000 & 1 & 1 \\
\hline $\operatorname{chr}$ & $\mathrm{BIN}+\mathrm{OH} \rightarrow \mathrm{BIN}^{*}+\mathrm{H}_{2} \mathrm{O}$ & $7.83 \times 10^{13}$ & 0 & 4,650 & 1 & 0.467 \\
\hline $\operatorname{chr}$ & $\mathrm{BIN}_{i \geq 10}+\mathrm{OH} \rightarrow \mathrm{BIN}^{*}+\mathrm{H}_{2} \mathrm{O}$ & $8.86 \times 10^{13}$ & 0 & 4,650 & 1 & 0.667 \\
\hline \multicolumn{7}{|c|}{ 3. HACA mechanism } \\
\hline \multicolumn{7}{|c|}{ 3a. H-abstraction } \\
\hline $\operatorname{chr}$ & $\mathrm{BIN}^{*}+\mathrm{H}_{2} \rightarrow \mathrm{BIN}^{*}+\mathrm{H}$ & $7.83 \times 10^{13}$ & 0 & 16,000 & 1 & -1.1 \\
\hline $\operatorname{chr}$ & $\mathrm{BIN}+\mathrm{H} \rightarrow \mathrm{BIN}^{*}+\mathrm{H}_{2}$ & $3.54 \times 10^{13}$ & 0 & 16,000 & 1 & 0.467 \\
\hline \multicolumn{7}{|c|}{ 3b. Acetylene growth } \\
\hline grow & BIN $*+\mathrm{C}_{2} \mathrm{H}_{2} \rightarrow$ products $+\mathrm{H}$ & $3.00 \times 10^{6}$ & 1.787 & 3,260 & 1 & 0.616 \\
\hline grow & $\mathrm{BIN}^{*}+\mathrm{C}_{2} \mathrm{H}_{2} \rightarrow$ products $+\mathrm{H}$ & 3.00 & 1.787 & 3,260 & 1 & 1.616 \\
\hline \multicolumn{7}{|c|}{ 4. $P A H$ condensation } \\
\hline cond & $\mathrm{A}_{i}+\mathrm{BIN} \rightarrow$ products $+\mathrm{H}$ & $3.00 \times 10^{13}$ & 0.5 & 15,000 & 0.35 & 0.59 \\
\hline cond & $\mathrm{A}_{i}+\mathrm{BIN}^{*} \rightarrow$ products & $8.00 \times 10^{12}$ & 0.5 & 0 & 0.35 & 0.59 \\
\hline cond & $\mathrm{A}_{i}+\mathrm{BIN} \rightarrow$ products & $8.00 \times 10^{12} \times \gamma_{1}$ & 0.5 & 0 & 1 & $1 / 6$ \\
\hline \multicolumn{7}{|c|}{ 5. Oxidation } \\
\hline ox & $\mathrm{BIN}+\mathrm{OH} \rightarrow$ products $+\mathrm{HCO}$ & $3.00 \times 10^{12}$ & 0 & 10,600 & 1 & -0.423 \\
\hline ox & $\mathrm{BIN}^{*}+\mathrm{O} 2 \rightarrow$ products $+2 \mathrm{CO}$ & $4.30 \times 10^{11}$ & 0 & 8,000 & 1 & $2 / 3$ \\
\hline ox & $\mathrm{BIN}^{*}+\mathrm{O} 2 \rightarrow$ products $+2 \mathrm{CO}$ & $8.60 \times 10^{7}$ & 0 & 8,000 & 1 & $5 / 3$ \\
\hline \multicolumn{7}{|c|}{ 6. Oxidation-induced fragmentation } \\
\hline frag & $\mathrm{BIN}_{i \geq 10}^{*}+\mathrm{O} 2 \rightarrow$ products $+2 \mathrm{CO}$ & $4.30 \times 10^{-2}$ & 0 & 8,000 & 1 & $2 / 3$ \\
\hline frag & $\mathrm{BIN}^{*}{ }_{i \geq 10}+\mathrm{O} 2 \rightarrow$ products $+2 \mathrm{CO}$ & $4.30 \times 10^{11}$ & 0 & 8,000 & 1 & $-1 / 3$ \\
\hline \multicolumn{7}{|c|}{ 7. Coalescence and agglomeration (coagulation) } \\
\hline coag & $\mathrm{BIN}+\mathrm{BIN}^{*} \rightarrow$ products $+\mathrm{H}$ & $2.00 \times 10^{13}$ & 0.5 & 15,000 & 1 & 0.35 \\
\hline coag & $\mathrm{BIN}^{*}+\mathrm{BIN}^{*} \rightarrow$ products & $8.00 \times 10^{12}$ & 0.5 & 0 & 1 & 0.35 \\
\hline coag & $\mathrm{BIN}+\mathrm{BIN} \rightarrow$ products & $8.00 \times 10^{12} \times \gamma_{1}$ & 0.5 & 0 & 1 & $1 / 6$ \\
\hline coag & $\mathrm{BIN}+\mathrm{BIN} \rightarrow$ products & $8.00 \times 10^{12} \times \gamma_{2}$ & 0.5 & 0 & 1 & $1 / 6$ \\
\hline
\end{tabular}

1. Units are in cal, mole, $\mathrm{cm}, \mathrm{s}$.

2. $\mathrm{T}$ is the flame temperature. $\mathrm{R}$ is the universal gas constant.

3. $n_{C}^{\prime}$ is the carbon number of the aromatics or lumped species except in reactions in which more than one aromatic or lumped species are involved, where it represents the average carbon number.

4. $\gamma_{1}$ and $\gamma_{2}$ are hydrogen content and size dependent coagulation efficiencies of coalescence and agglomeration, evaluated at $\mathrm{T}=1500 \mathrm{~K}$ (see Refs. [51, [54]). 
sion of both the gaseous and particle phases, thermophoresis of particles and radiation losses by using a discrete transfer method. A detailed description of the numerical setup can be found in Refs. [51, 54. Figure 1 shows the comparison between the predicted and measured results for the Santoro flame. Overall, the model is in very good agreement with experiments and can replicate both soot formation and burn-out in this flame. There are some differences between the sectional approach of this work (reduced) and the original multi-sectional (detailed) method [54, but they generally show a very similar performance. In particular, the predictions with the reduced approach are in excellent agreement with the maximum soot volume fraction (SVF), $f_{v}$, in the annular region of the flame and the model accurately captures the integrated soot volume fraction (ISVF) across all radii. Radial profiles of temperature, acetylene, $\mathrm{OH}$ and $f_{v}$ are also well represented. Predictions of temperature are somewhat high on the flame centreline, as well as in the region where the SVF maximises and the experimental uncertainty is larger. An under-prediction of the SVF on the flame centreline is also observed, similar to other models (e.g., 65]). It is worth noting that on the centreline, the discrepancy between the detailed and reduced model is the greatest in terms of spatial distribution. This discrepancy might play a role in turbulent configurations, and it should be further improved in future works.

\subsection{Investigated burner}

The investigated burner, developed at the University of Cambridge, is based on a bluff-body swirl-stabilised ethylene/air burner operating at atmospheric pressure [25, 26, 27. A picture and a schematic of the rig are given in Fig. 2 . 245 This configuration is able to reproduce the key features of a typical RQL configuration by allowing air to enter through three separate streams: (i) an inner swirling flow (primary air), located in the annular gap of the bluff body and generated by means of an axial swirler; (ii) a concentric swirling flow (secondary air), created through tangential ports in an annular chamber; (iii) four trans- 

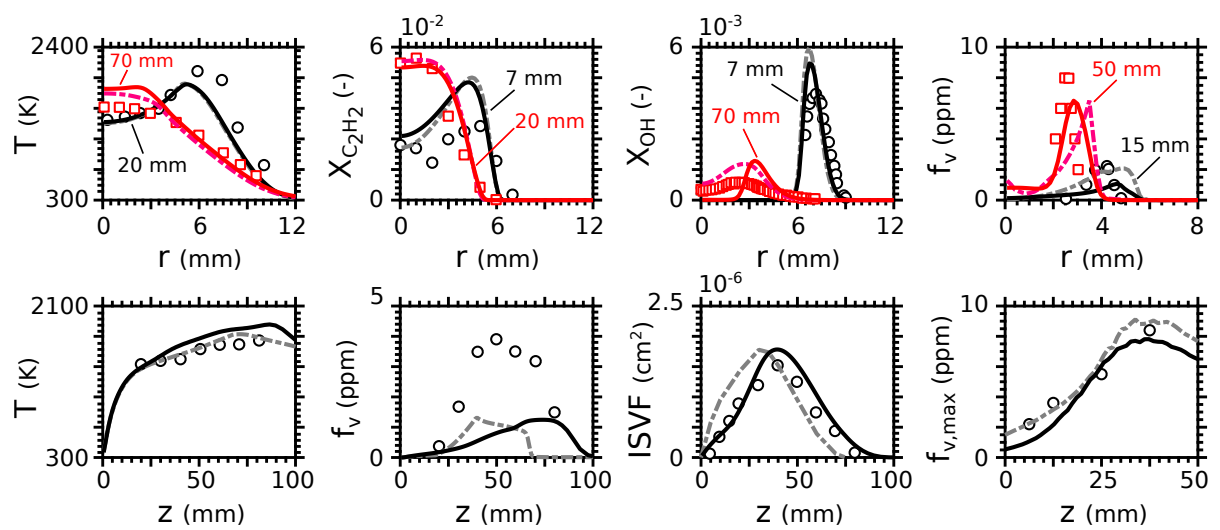

o exp - detailed - reduced

Figure 1: Predicted vs. measured temperature, species and soot volume fraction profiles in the laminar ethylene co-flowing flame. Top: profiles at the axial heights indicated as functions of radial distance, $r$, from flame centreline. Bottom: selected quantities along the flame centreline, $z$, integrated soot volume fraction (ISVF) over radius and local maximum soot volume fraction in the annular region of the flame. The detailed approach can be found in Ref. [54]. The reduced approach is from this work. Experimental data are from Refs. 66 64].

the dilution ports of an aviation RQL combustor and can be adjusted at various heights to alter the residence time and mixing rates in the primary and dilution zones. The fuel is injected through an axial jet located at the centre of the bluff body. Ethylene was selected as a model fuel thanks to its simpler and better validated chemistry compared to kerosene, but also to avoid the additional degree of complexity related to liquid spray. Further details regarding the experimental rig can also be found in Refs. 25, 26, 27, 28.

In this study, two operating conditions are investigated, sharing the same global equivalence ratio, $\phi_{g}=0.36$, and fuel velocity, $U_{f}=15.7 \mathrm{~m} / \mathrm{s}$, but different mass flow ratio between the primary air and the transverse jets stream. In case $A$ ( $0 \%$ dilution), all the air mass is injected through the primary air stream with a bulk velocity of $U_{p}=13.0 \mathrm{~m} / \mathrm{s}$. In case $B$ ( $40 \%$ dilution), $40 \%$ of the air is equally split to the transverse jets, corresponding to four dilution air streams of $61.3 \mathrm{~m} / \mathrm{s}$, while the remaining part is injected through the primary air stream with $U_{p}=7.9 \mathrm{~m} / \mathrm{s}$. In both cases, the secondary air stream is 

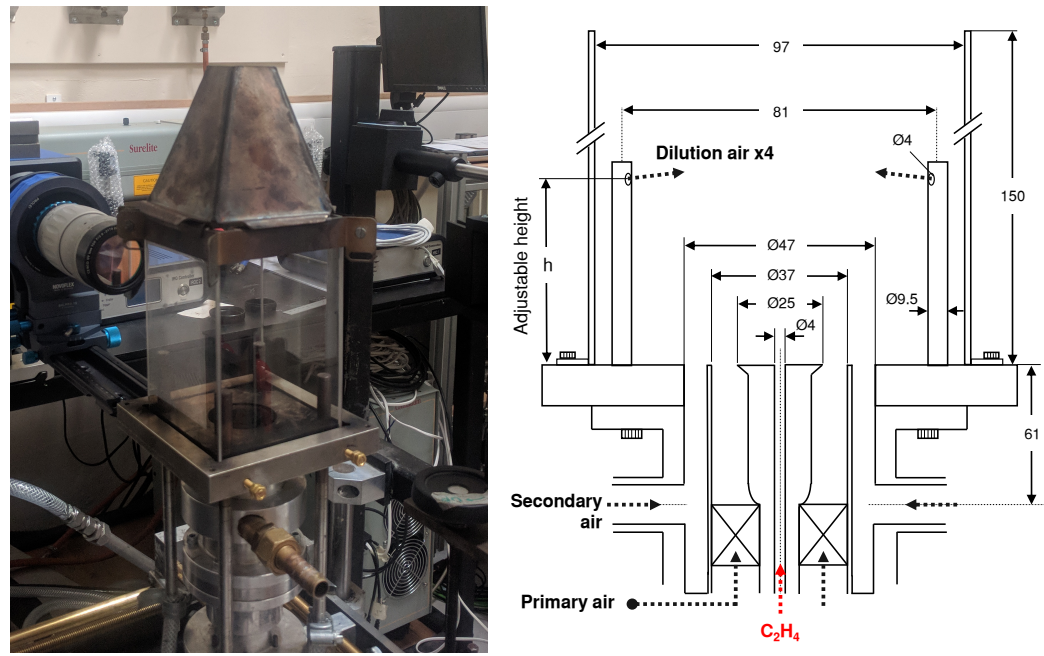

Figure 2: Picture of the Cambridge RQL burner (left) and schematic adapted from [31] (right).

deactivated, and the height of the dilution jets is $h=47 \mathrm{~mm}$. Previous experimental studies in this burner have shown that these conditions drastically affect soot emission [25, 26, 27, 28. Similar trends have been observed via numerical investigations in similar conditions with a slightly leaner global equivalence ratio 48 .

\subsection{Numerical setup}

A similar numerical setup to Refs. [31, 48] is adopted here. The computational domain reproducing the experimental rig is shown in Fig. 3 . A plenum has been placed around the combustor whereas the inlet of the primary air has been located downstream the axial swirler. As far as the transverse jets are concerned, the entire ducts, from the base of the burner to the jet orifice, have been included in the domain. The fuel inlet has been placed at the exit of the fuel channel, located on the top surface of the bluff body. The LES equations are solved in a fully tetrahedral mesh of about 19.5 million cells with a maximum grid size of $0.8 \mathrm{~mm}$ in the flame region and local refinements close to the fuel inlet and the exit of transverse jets (see Fig. 3 for a detailed view). The mesh fulfilled Pope's criterion for LES in the entire region of interest, resolv- 
ing at least $85 \%$ of turbulent kinetic energy [66]. CMC equations are solved in a polyhedral grid of 1024 cells with refinement in the flame region, where high mixture fraction gradients are expected, and hence high values of $\tilde{N}$. In the region of interest, individual CMC cells contain a range of 5,000 to 15,000 LES cells. Details of the CMC mesh are also shown in Fig. 3. DNS studies of sooting flames [45, 46, as well as LES studies [39, 48, show that conditional fluctuations of soot quantities are large even when conditional fluctuations of soot precursors are small. This phenomenon takes place at both the large and small scales, and it is more pronounced when aromatics-based pathways are included in the soot model [47, 29]. As a result, a finer CMC mesh, aiming to better resolve the gradients of conditional quantities in the soot production and oxidation regions, may improve quantitative soot predictions. This has also been suggested for conditions with localised extinction [38, where conditional gradients are also large. However, in the flames investigated here, there is not significant presence of localised extinction, so the gradients of $\widetilde{N}$ from region to region will not result in very large differences in the underlying combustion field.

Concerning the LES equations, second-order accurate central differencing schemes are employed for spatial discretisation whereas a second-order implicit backward scheme is adopted for time derivatives [67]. A second-order accurate and bounded Gamma differencing scheme is used to control small over- and under-shoots 68 for the filtered mixture fraction and its sub-grid scale variance. Velocity profiles, obtained from RANS computations of the full system with the axial swirler included (see Fig. 3), are imposed at the primary air inlet whereas a uniform axial velocity is used for the inlet of the transverse jets. A constant pressure condition of $1 \mathrm{~atm}$ is used at the outlet, and all solid surfaces are modelled as adiabatic walls with the no-slip condition. As far as the fuel inlet is concerned, a synthesised turbulent inlet is employed by adding whitenoise random components to a uniform velocity profile 69, assuming isotropic turbulence and imposing a turbulence intensity of $5.3 \%$ (estimated from fullydeveloped pipe flow). An asymmetric time filter is used for temporal coherence, 
as in Ref. [70]. Furthermore, a low-velocity air co-flow is imposed at the base of the plenum to improve the numerical stability of the computations.

Following standard practice, an operator splitting technique is implemented for the solution of the CMC equations. Transport in physical space is solved first (see terms T1-T3 in Eq. 1), followed by diffusion in mixture fraction space (term T4) and the chemical source term integration (term T5) as the last step. In previous works with LES-CMC and two-equation acetylene-based models for soot [30, 31, 48, the chemistry integration was split into two steps by solving the gaseous and particle phase chemistry separately. The error introduced from the latter split was evaluated through 0D-CMC calculations, i.e., the solution of CMC Eq. 1 without transport in physical space and imposed $N_{0}$. The error 325 was found to be negligible when the same time step of the LES-CMC computation was used, thus allowing for use of the splitting of gas-phase and soot chemistry to speed up the computation without accuracy penalties 31. However, this error was assessed again for the kinetic mechanism and soot model of this study and was found to be significant because of the presence of aromaticsbased pathways. Consequently, a single operator splitting step was chosen here for chemistry integration. For this step, the SpeedCHEM solver is used, which significantly speeds up the computation by exploiting a sparse Jacobian formulation and tabulation of temperature-dependent properties [71]. Note that with this approach, all the effects of particle formation, growth, and oxidation on 335 the gaseous phase are considered, i.e., the gaseous and particle phases are fully coupled.

The simulations are initialised from previous LES using different chemistry [48. Statistics are collected over two flow-through times after one flowthrough time of simulation corresponding to about $10 \mathrm{~ms}$ for an axial burner length $L=150 \mathrm{~mm}$. Simulations were performed on $2562.6 \mathrm{GHz}$ processors with $6 \mathrm{~GB}$ of RAM per processor. The computation of $1 \mathrm{~ms}$ of physical time requires almost $70 \mathrm{~h}$. 


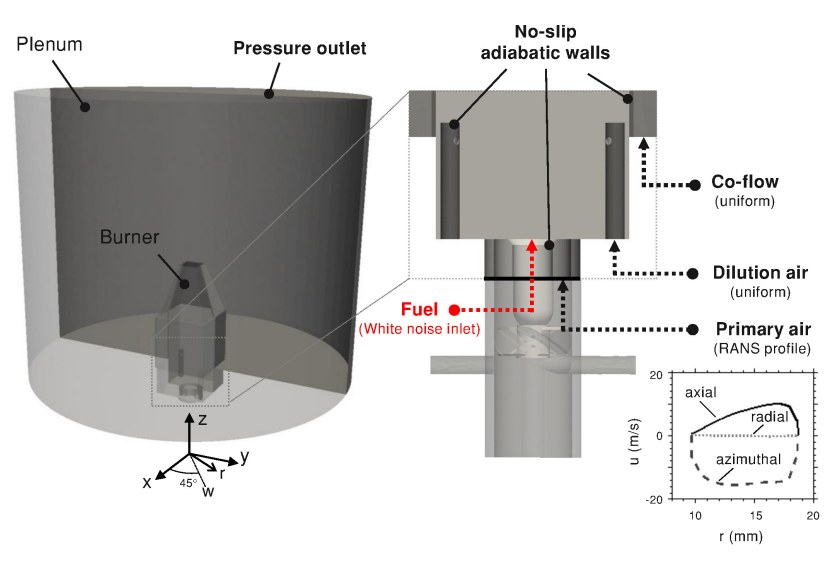

(a)

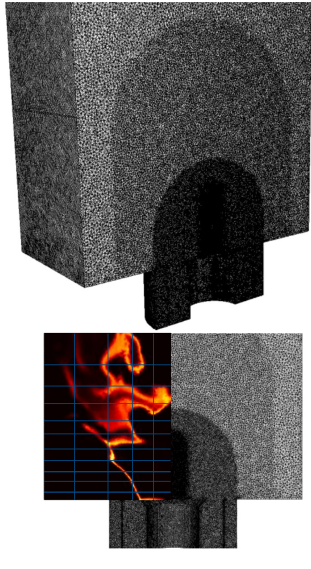

(b)

Figure 3: (a) Computational domain with location of the various inlets and boundary conditions. The full system geometry, including the axial swirler, used in the preliminary RANS computations is also indicated. Additionally, the components of the mean velocity imposed at the primary air inlet of case $B$ are shown. (b) LES mesh and outlines of CMC mesh in the region of interest with superimposed contours of $\mathrm{OH}$ mass fraction for a time instant of case $A$ (bottom, left half). 


\section{Results and discussion}

\subsection{Flow field and flame shape} affects both the primary zone and mixing is important for the remainder of the discussion.

Figure 4 shows the time-averaged axial velocity in a stream-wise cross-section for the two cases investigated in this study. Two different regions in the flow field may be distinguished: an outer recirculation zone (ORZ) enclosed at the burner corners, and an inner recirculation zone (IRZ) formed due to the combined effect of the bluff body and the swirling flow. The non-diluted case $A$ is characterised by a long IRZ, whereas case $B$ shows a shorter IRZ confined below the transverse jets caused by the additional action of the dilution air. As also observed in Ref. [31, the time-averaged velocity field is slightly asymmetric with the fuel jet bending to one side. This is probably due to a slow precession of the fuel jet, which is not entirely captured in the simulated time. Although the combustion chamber is not axisymmetric, for the domain of interest used in the comparison with experiments (see Fig. 4), a symmetric behaviour around the burner centreline is expected on average. Therefore, to extract more information out of the simulation data, mean unconditional fields will be later reported after both time- and azimuthal averaging by considering multiple planes separated by a constant azimuthal angle of 1 degree.

For both investigated cases, the IRZ is generally characterised by the presence of rich mixture, as shown by the mean mixture fraction fields in Fig. 5 . Hereafter, the IRZ is referred to as the burner primary zone, consistent with the RQL concept. In the presence of dilution air (case $B$ with $40 \%$ dilution), a leaner primary zone is observed corresponding to a smaller spatial extent of the stoichiometric region induced by the penetration of the transverse jets and the stronger back-flow in the burner centreline. The latter also affects turbulence and velocity fluctuations leading to an enhanced time variation of the local mixture fraction (and hence mixing), as shown by the higher values of the mixture fraction root mean square in Fig. 5. The observation that dilution air 

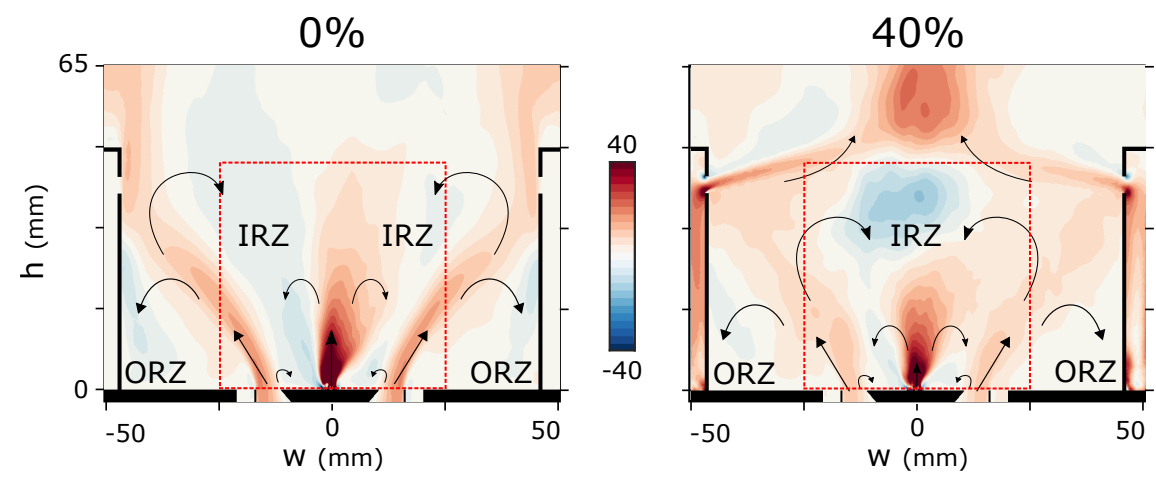

Figure 4: Time-averaged axial velocity $(\mathrm{m} / \mathrm{s})$ in a stream-wise cross-section with indication of the inner (IRZ) and outer recirculation zones (ORZ) for the two cases investigated in this study (case $A$ : $0 \%$ dilution, case $B: 40 \%$ dilution). The dash-red rectangles show the domain of interest, restricted in a $50 \times 50 \mathrm{~mm}^{2}$ domain away of the transverse jets, for comparison with experimental data.

The mean flame shape has been experimentally investigated through line-ofsight and subsequent inverse Abel-transformed $\mathrm{OH}^{*}$ chemiluminescence measurements 26, 27. The $\mathrm{OH}^{*}$ distributions can be used to indicate the location containing reacting regions and compared with the mean heat release rate (HRR) from the LES. Both cases show an intense reacting region along the primary air shear layer, which is confined below the transverse jets. However, the diluted case shows a more uniform signal distribution in the primary zone, and a stronger signal near the bluff body, likely to be caused by the different fuel distribution as the fuel jet penetrates less due to the increased reverse flow and the higher mixture fraction fluctuations in that region. The simulated HRR results show qualitatively the same features with the $\mathrm{OH}^{*}$ images and replicate the variations with dilution. Although the $\mathrm{OH}^{*}$ chemiluminescence data cannot be considered quantitative, the numerical predictions are satisfactory, suggesting that the mean flame shape and presumably the mixture fraction field are reasonably well predicted. 

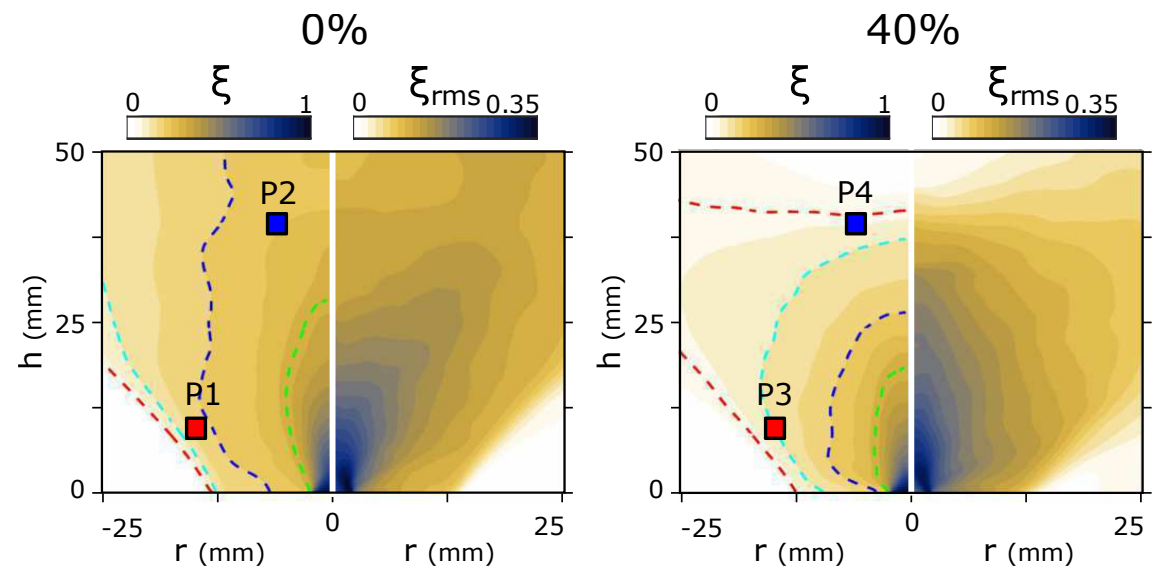

Figure 5: Mean mixture fraction (left-half plots) and root mean square (rms) of mixture fraction (right-half plots) for the two cases investigated in this study (case $A$ : $0 \%$ dilution, case $B: 40 \%$ dilution). Green line: $\xi=0.3$; blue line: $\xi=0.2$; cyan line: $\xi=0.12$; red line: $\xi=\xi_{s t}=0.063$; purple line: $\xi=0.03$. Points P1-P4 correspond to the locations where the soot PSDs are analysed.
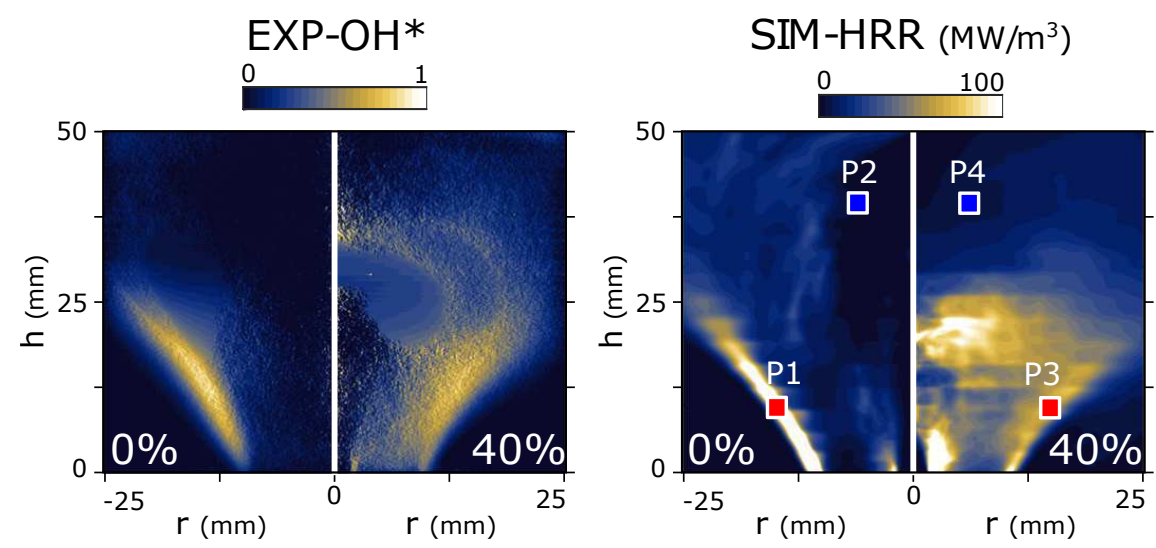

Figure 6: Comparison between experimentally obtained inverse Abel-transformed mean $\mathrm{OH}^{*}$ chemiluminescence (left) and mean heat release rate from the simulation (right). See Refs. 26] 27. for the experimental methodology. Points P1-P4 correspond to the locations where the soot PSDs are analysed. 


\subsection{Sooting flame structure}

Selected instantaneous flow quantities are presented in Fig. 7. A region of

(via acetylene surface growth and $\mathrm{PAH}$ condensation) and enhances oxidation in regions with substantially high SDR.

Soot evolution has been also investigated through qualitative Laser-Induced 

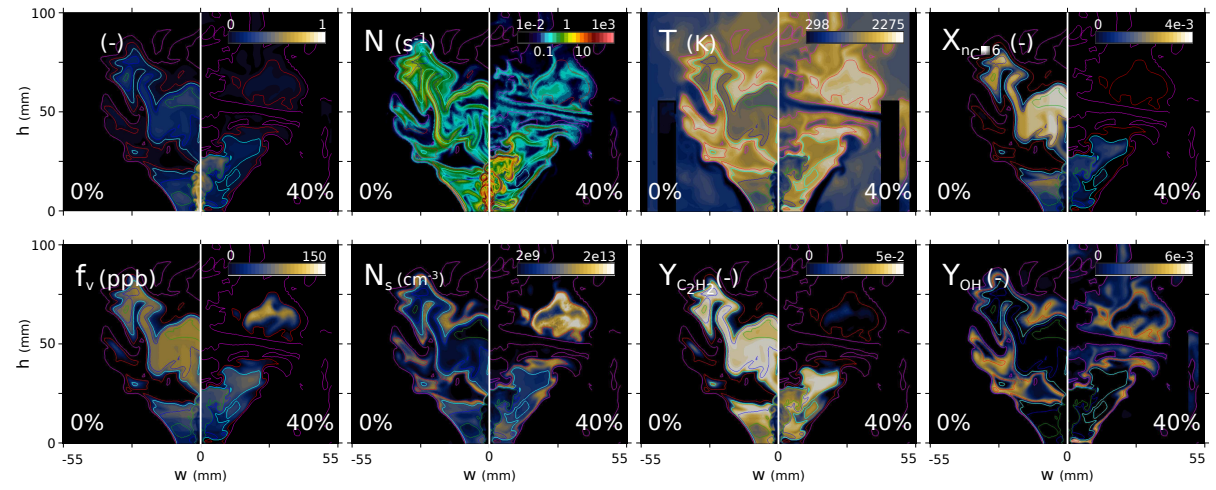

Figure 7: Selected instantaneous filtered quantities in a stream-wise cross section for case $A$, $0 \%$ dilution, (left-half plots) and $B, 40 \%$ dilution (right-half plots). $X_{n_{C} \geq 6}$ corresponds to the sum of mole fractions of aromatic species with carbon number greater or equal than 6 . Mixture fraction iso-lines: green $=0.3$, blue $=0.2$, cyan $=0.12$, red at stoichiometric and magenta at half the stoichiometry. The symbol $\sim$ (indicating filtered values) is dropped here.

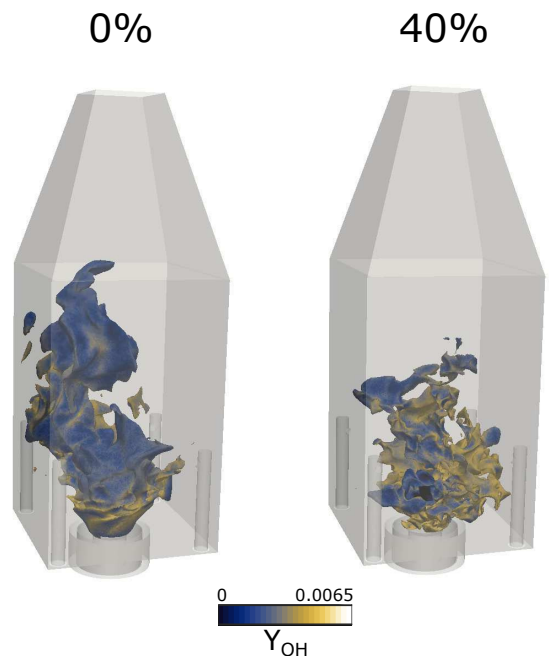

Figure 8: Instantaneous iso-surface of the stoichiometric mixture fraction coloured with $\mathrm{OH}$ mass fraction. 
Incandescence (LII) measurements [26, 27]. In Fig. 9, normalised experimental LII signals are compared side-by-side with the predicted soot volume fraction (SVF) fields. To facilitate the interpretation of the simulation results, both the total SVF and the SVF of nanoparticles are compared. It is known that LII favours the detection of larger particles, with the LII signal expected to arise from particles approximately in the range 5-100 $\mathrm{nm}$ [1. The inclusion of both particle fields indicate better the ability of the method in capturing the measured location of soot presence and the relative magnitude with varying dilution and allow some insights to be drawn despite the uncertainty involved with the interpretation of the LII signal.

Without dilution air, the time-averaged LII signal was found to be persistent throughout the given field of view with higher concentrations near the bluff body and in a region near the primary air shear layer where the simulation predicts a significant back-flow (see Fig. 4). LII signal is also present further downstream in the primary zone and the centreline, possibly due to the transport of soot particles from the shear layers towards the IRZ. With dilution air, the mean LII signal no longer persists downstream, and a drastic reduction occurs at about half the height of the transverse jets, which is probably a result of enhanced oxidation induced by the penetration of the transverse jets in the primary region. This can be better appreciated by the $\mathrm{OH}^{*}$ chemiluminescence and HRR fields of Fig. 6. which indicate the presence of an intense reacting region at that location.

${ }_{440}$ Note also the severely decreased magnitude of the LII signal in the case with dilution.

Given the high complexity of this configuration, the success of the simulation is considered fair. The region with high values of total SVF is smaller in the case with dilution, and no more soot is evident downstream of the jets, consistent with experiment. It is observed that at the location close to the bluff body, soot particles are present in both cases, but these are found mostly in the nanoparticle range; hence they do not significantly contribute to the total SVF. In addition, soot particles are not found in substantial quantities at the primary air shear layer of case $A$. As previously discussed, this is possible either through 
${ }_{450}$ a reduction of available precursors (PAH species, in particular) due to SDR effects or the enhanced oxidation due to the penetration of soot towards the oxidiser stream. These effects will be further analysed later in Section 3.4

The mean LII signal intensities reported here for case $B$ were lower compared to case $A$ by a factor of 16 . Further measurements have to be performed in order to convert the qualitative LII signal to quantitatively determined soot volume fraction, however, this significant difference clearly shows the lower soot formation tendency in the diluted case $B$. In the simulation, the azimuthally-averaged mean soot volume fraction in the region of interest is about 3 times lower for the diluted case compared to case $A$. In Appendix $\mathrm{B}$, a qualitative comparison with experimentally obtained PAH-PLIF is also shown that is consistent with the main conclusions in this section.

\subsection{Analysis of soot particle size distributions}

The above-mentioned soot tendency differences are closely related to the evolution of soot particle size distributions (PSDs). Figure 10 shows typical timeaveraged soot PSDs taken at locations inside the primary zone (see Figs. 5, 6 and 9 for locations) and at the burner exit. First, locations P1-P4 are analysed, which correspond to regions inside the primary zone (P1-P2 for case $A$ and P3-P4 for case $B$ ). As indicated by their standard deviation, the modelled soot PSDs shape in these locations show a large scatter, which appears to be significantly higher for the case $B$, probably due to more intense mixing in the primary zone when dilution air is present. Consistent with the observed unconditional soot fields, case $A$ is generally characterised by higher volume fractions but also a larger mean particle since the soot volume fraction PSD is shifted towards higher $D_{m m}$. In addition, a difference in the soot number density PSD is observed. Interestingly, the diluted case $B$ is characterised by a largely sustained uni-modal mean shape while case $A$ is showing an alternating uni-/bi-modal behaviour, as suggested by the difference between locations P1 and P2. This observation is of great interest and may prove key to understand the effects of turbulence on the soot PSDs. 


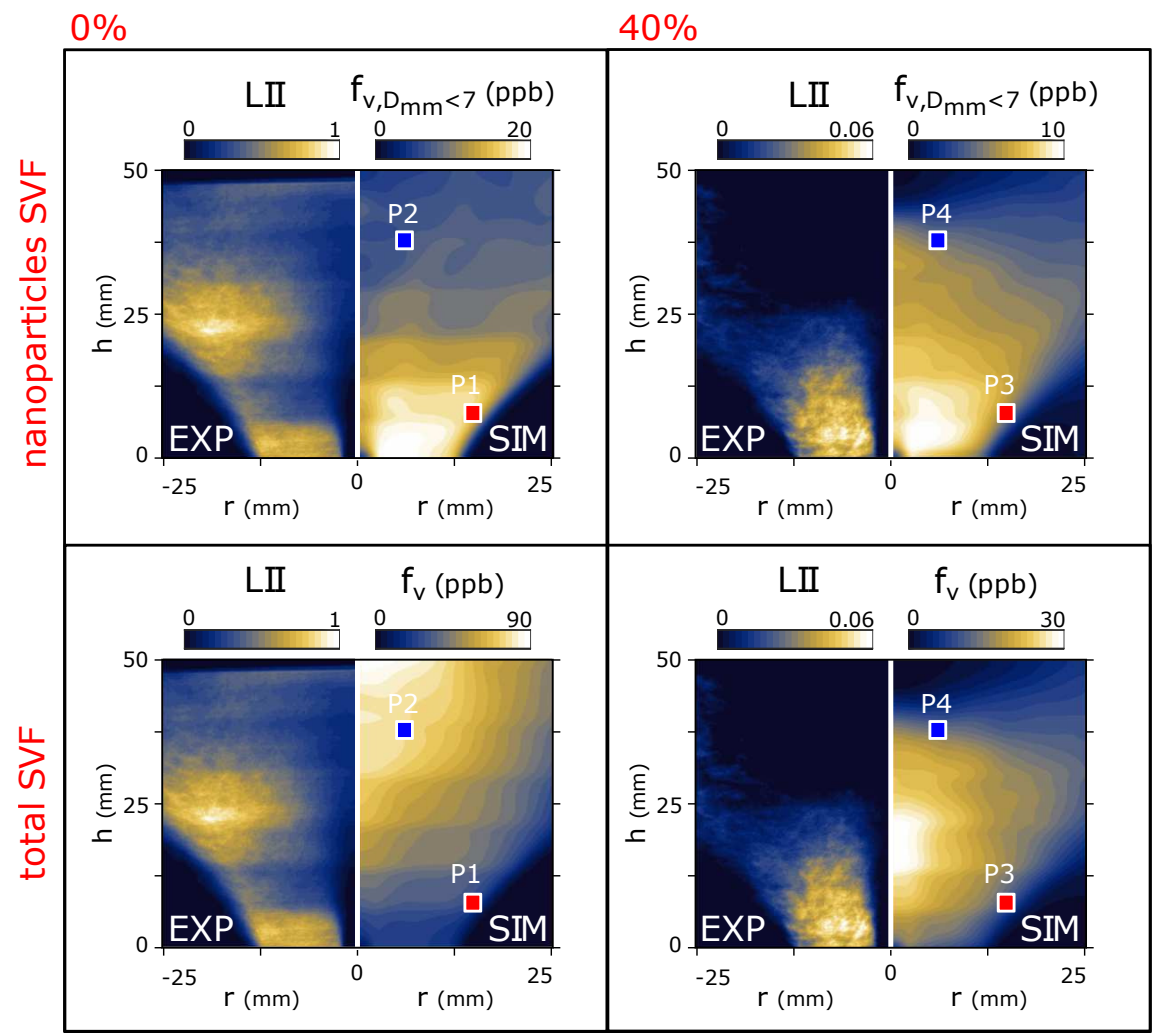

Figure 9: Comparison between experimental mean LII intensity (left-half plots) and mean soot volume fraction (SVF), $f_{v}$, predicted by LES-CMC (right-half plots) for the two cases investigated in this study (case $A: 0 \%$ dilution, case B: $40 \%$ dilution). Measurements are LII@430 $\pm 25 \mathrm{~nm}$ excited at $532 \mathrm{~nm}$ (see 26] 27, 28, for methodology). Experimental values are normalised with the maximum signal of case $A$. Both nanoparticles SVF (top) and total SVF (bottom) from the simulation are reported. Points P1-P4 correspond to the locations where the soot PSDs are analysed. 
Based on the current consensus on laminar sooting flames [3], this variation may be explained in terms of residence time under favourable fuel-rich conditions. More specifically, soot surface growth, condensation and coagulation reactions, which are known to be responsible for the soot PSD bi-modality, may occur in timescales at least comparable with the residence time in the primary zone of condition $B$, eventually leading to the formation of smaller particles. This is essentially a result of finite-rate chemistry effects and the underlying mixing field affected by the additional dilution air and also associated with a lower mean residence time. Nevertheless, on average, all locations are characterised by a uni-modal soot number density PSD, consistent with experimental observations [28 in this burner and other turbulent jet flames [72, 73]. As discussed in Ref. [74, this can be attributed to time-averaging in a turbulent flow, which for point P2, in particular, leads to a loss of bi-modality as the second PSD peak may be found at different diameters with varying time.

As far as the soot PSDs downstream of the primary region are concerned, predictions at the burner exit (noted as E) are also reported in Fig. 10. The predictions indicate the dominance of nanoparticles at the exit with some differences between the resulting PSD, which also have an effect on total soot quantities. In terms of the total soot number density, $N_{s, t o t a l}^{s i m}$, the diluted case shows a decrease of about $60 \%$ compared to the undiluted case $A$, whereas a total SVF leakage, $f_{v, \text { total }}^{\text {sim }}$, decrease of about $55 \%$ is observed with dilution. Notably, case B shows a total number density of approximately $5.5 \times 10^{10} \mathrm{~cm}^{-3}$ and a total SVF of $0.06 \mathrm{ppb}$, which agree reasonably well with recently obtained experimental measurements at the burner exhaust: $N_{s, t o t a l}^{e x p}=8.6 \times 10^{8} \pm 1.7 \times 10^{8}$ $\mathrm{cm}^{-3}, f_{v, \text { total }}^{\text {exp }}=0.03 \pm 0.01 \mathrm{ppb}[28]$.

Figure 11 shows the comparison between the time-averaged simulated and the measured 28] PSDs obtained at the exhaust. It is found that in the highdilution case, a fairly good match is obtained with some quantitative differences, also observed from the total soot quantities reported above. However, in the no-dilution case, the prediction shows too few and too small particles compared to the experiment even if predictions in the primary zone show the existence 

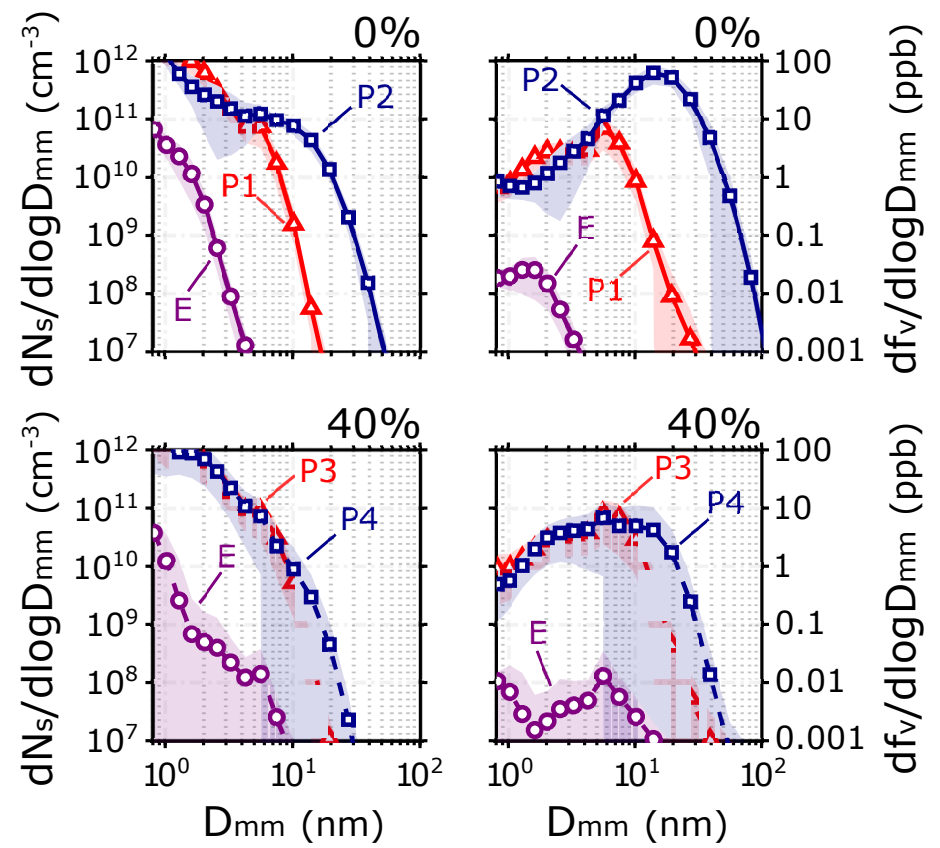

Figure 10: Mean particle size distributions (PSDs) of soot number density (left) and soot volume fraction (right) at selected points P1-P2 (case $A$ ), P3-P4 (case B), and at the burner exit (noted as E). PSDs of case A, $0 \%$ dilution, are reported (top) and case B, 40\% dilution (bottom). Filled colour shows \pm one standard deviation from the mean. The locations of points $\mathrm{P} 1$ and $\mathrm{P} 2$ are indicated in Fig. 7 

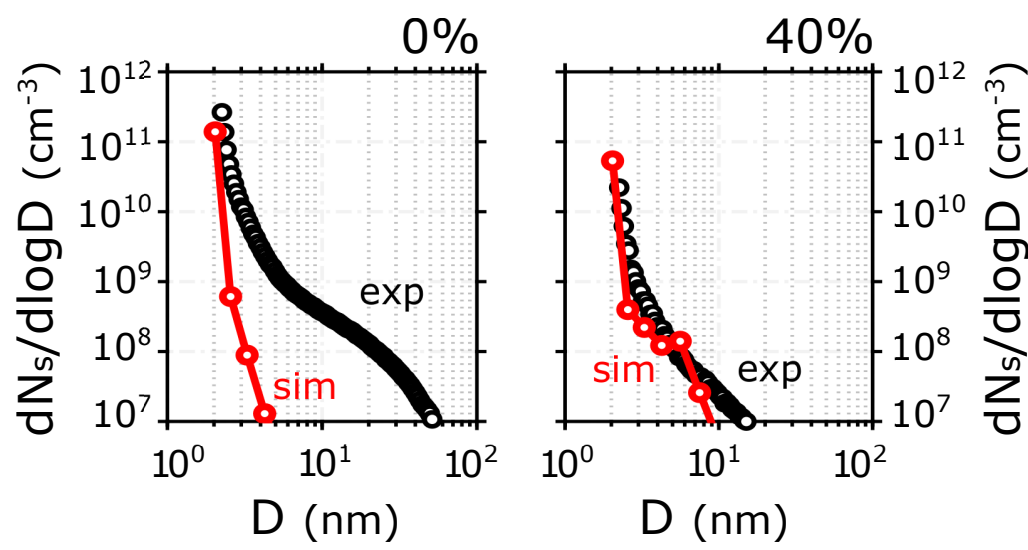

Figure 11: Comparison between time-averaged experimental (exp) and simulated (sim) soot particle size distributions (PSDs) at the exit of the combustor. D refers to mobility diameter for experiments and mean mass diameter, $D_{m m}$ for simulations. The first five lumped species (see Table 1) have been summed to better replicate the lowest size cut-off of the experimental measurements [28].

of more and larger soot particles, especially for case $A$ (see Fig. 10). The latter quantitative comparison indicates an over-prediction of oxidation which significantly modifies the PSD (towards smaller $D_{m m}$ and $N_{s}$ ) downstream the primary zone up to the burner exit.

\subsection{Analysis in mixture fraction space}

The online solution of conditional scalars allows the inclusion of a detailed chemistry model, but also allows history, micro-mixing and turbulent transport to be included in the soot prediction. Figure 12 shows the evolution of the CMC solution at one representative location inside the primary region. Due to its location inside the fuel-rich recirculation zone and frequently high probability of rich mixture fractions, it is characterised by high values of pyrolysis products, soot mass and number density. In addition, all reported variables show a large dispersion which is mostly attributed to finite rate chemistry effects induced by turbulent transport (terms T1-T3 in Eq. 1) and large variations in micro-mixing (term T4). It is noteworthy, however, that aromatic species (here naphthalene $\mathrm{A}_{2}$ ) and soot related quantities are more susceptible to the above, as can be 
seen from the changes in the location of the peak values with respect to mixture fraction. Moreover, the peak soot volume fraction here can be found in a wide range of mixture fractions in contrast to previous studies on this burner using simplified chemistry [31, 48. The sensitivity of aromatics and soot on turbulent transport and scalar dissipation rate (SDR) history is known from DNS [29, 47, and the method appears to replicate well these effects since LES-CMC is based on the time-resolved flame structure. At this point, however, it is essential to note that despite the more elaborate treatment of turbulence-chemistry effects, uncertainties related to the aromatics chemistry, hence the transition to soot particles, and soot evolution impact soot predictions severely and further work is required on this end [5]. Data-sets in laminar conditions more relevant to the Cambridge RQL burner and aviation combustors in general, e.g., counter-flow configurations with high and oscillating strain rates, could prove very helpful on this topic and assist with PAH and soot evolution kinetics validation [75].

Furthermore, it is of interest to compare conditional distributions against the Santoro laminar flame simulation presented in Section 2.2. This allows for an evaluation of the CMC solutions against calculations in physical space with different diffusivities for the gaseous and lumped species, as well as thermophoresis of particles. Figure 13 shows the Santoro flame solution in mixture fraction space plotted against two representative locations of the Cambridge RQL burner characterised by a low and high range of SDRs. It is evident that overall the CMC solutions give results that seem to reside within the equivalent SDR range of the laminar flame solutions. The assumption of unity Lewis number $(L e=1)$ shows that nanoparticles (associated with the total soot number density, $N_{s}$ ) penetrate the flame zone towards the oxidiser, however, the soot volume fraction is reasonably well located in $\eta$-space. The peaks of temperature and pyrolysis products, such as acetylene $\left(\mathrm{C}_{2} \mathrm{H}_{2}\right)$ and benzene $\left(\mathrm{A}_{1}\right)$ are also reasonably well located. From a soot evolution perspective, the turbulent flame does not behave as a quasi-steady laminar flamelet due to history and transport effects, as also concluded by Lindstedt and Louloudi [76] and so we may not expect complete agreement. Nevertheless, Figs 13a) and 13p) demonstrate that 
the error associated with the neglect of differential diffusion effects of soot may not be too large in the flames studied here.

The sensitivity of soot related quantities to SDR history and turbulent transport may also be investigated through the hierarchy between the various physical and chemical pathways of soot evolution. In Fig. 14 the total contributions of individual soot model source terms (see Eq. 3) are compared by showing reactions that affect primarily the soot mass, i.e., surface growth via $\mathrm{C}_{2} \mathrm{H}_{2}$, oxidation, and condensation via aromatics, or soot number density balance, i.e., nucleation, coagulation, and oxidation-induced fragmentation. Considering the wider conditional scatter, which is attributed to temporal variations in SDR, aromatics-based reactions, such as condensation and nucleation, seem to be the most susceptible to micro-mixing and turbulent transport. This is closely related to the sensitivity of aromatics to transport, as mentioned previously. In terms of soot mass, condensation dominates at regions of $\eta>0.12$, whereas oxidation reactions and acetylene-based growth are confined in a narrow range of mixture fractions found in the proximity of the stoichiometric mixture fraction. As far as the soot number density is concerned, oxidation-induced fragmentation reactions are responsible for a significant increase in soot number density around stoichiometry, whereas coagulation appears to balance out a significant number of soot particles across the whole mixture fraction space. The balance of the latter is crucial for the prediction of the soot PSD.

Because the various soot processes have very different rates across mixture 580 fraction space and are affected by micro-mixing to different extents, it is suggested that online solution of the flame structure such as that offered by LESCMC may offer greater generality in predicting PSDs for complex flames compared to tabulation-based approaches. However, the modelling of SDR and of differential diffusion effects makes the overall predictions sensitive to the choice 585 of the related sub-models. Finally, the localisation of the various processes in mixture fraction space, revealed in the laminar and turbulent simulations (see Figs. 12 14, suggests that when interpreting soot results from complex burners, attention should be given to the residence times in the various mixture fraction 

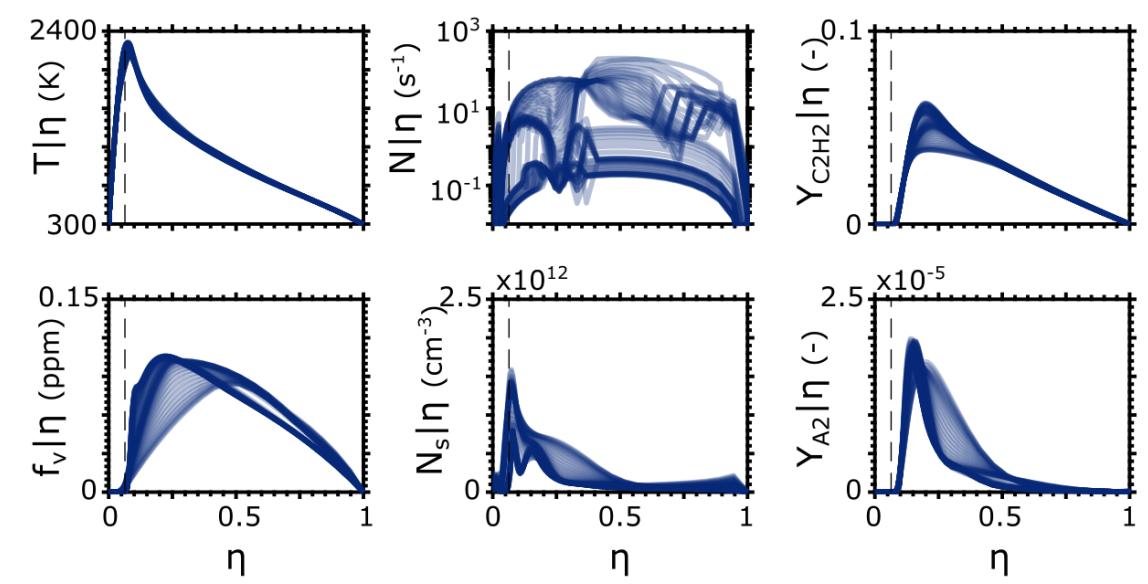

Figure 12: Solution in $\eta$ space at a location $(r=38, h=12 \mathrm{~mm})$ of case $A$ ( $0 \%$ dilution). Each line corresponds to a different time instant, uniformly sampled in a time period of $10 \mathrm{~ms}$. Dashed line: stoichiometry.

ranges.

\section{Conclusions}

A comprehensive soot modelling approach for turbulent flames has been successfully developed with the main objective to investigate the evolution of soot particle size distributions (PSDs) in a model Rich-Quench-Lean (RQL) burner, a configuration typical of aviation gas turbines. The method is based on LESCMC and a novel detailed kinetic mechanism of aromatic growth, particulate formation and oxidation, employing a sectional method for the particle phase. The model gives good predictions for a low-strain laminar co-flow flame. Two operating conditions for the RQL burner, having the same global equivalence ratio but a different ratio of dilution to total airflows, are investigated. The results show a reasonable agreement with experimental data in terms of reaction zone location, spatial distribution of the soot in the combustor, and their trends with changes in airflow split.

The instantaneous soot PSDs in the primary region were found to switch from a bi-modal to a uni-modal shape when dilution is activated, which is 

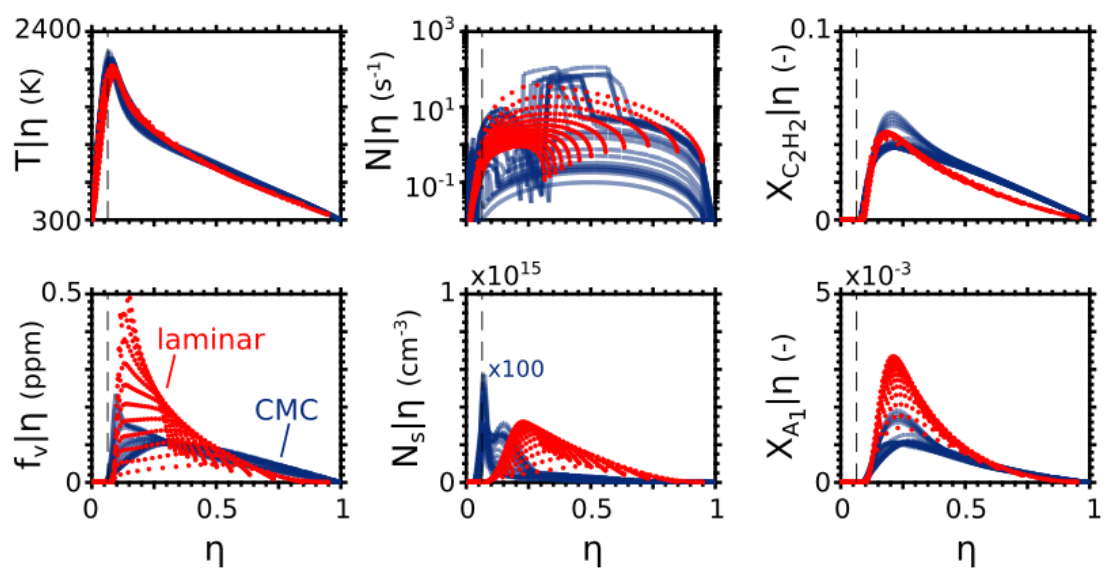

(a) Low SDR
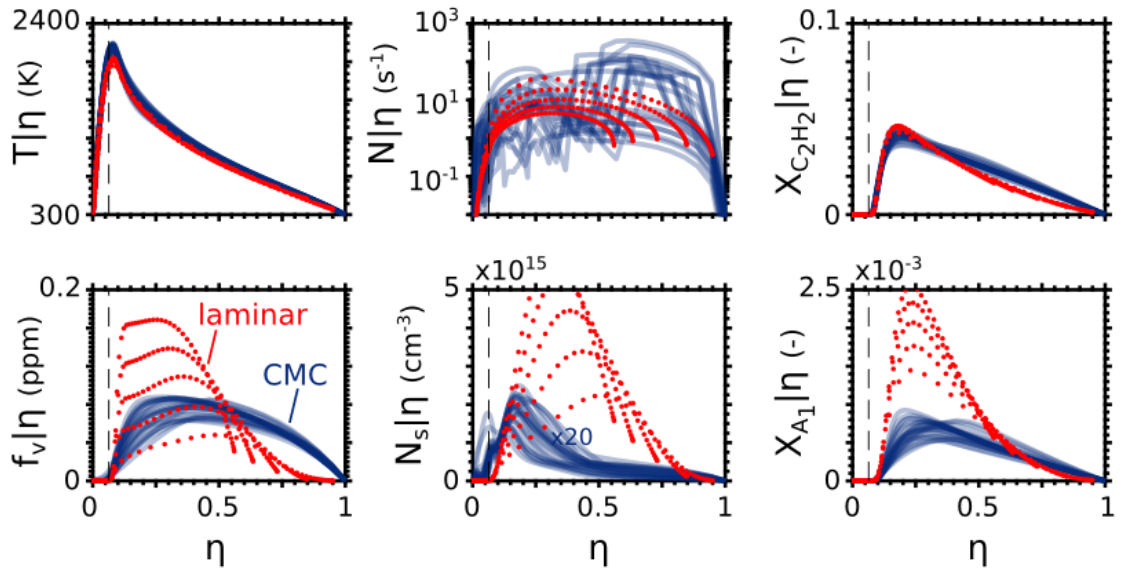

(b) High SDR

Figure 13: Solutions in $\eta$-space from CMC and the laminar co-flowing flame. Each CMC line corresponds to a different time instant, uniformly sampled in a time period of $10 \mathrm{~ms}$, extracted from the LES-CMC at representative locations of case $A$ ( $0 \%$ dilution) for (a) and $B(40 \%$ dilution) for (b). The laminar flame data are extracted from all cross-sections in the first (a) $4 \mathrm{~mm}$ and (b) $10 \mathrm{~mm}$ of the Santoro flame. Dashed line: stoichiometry. 

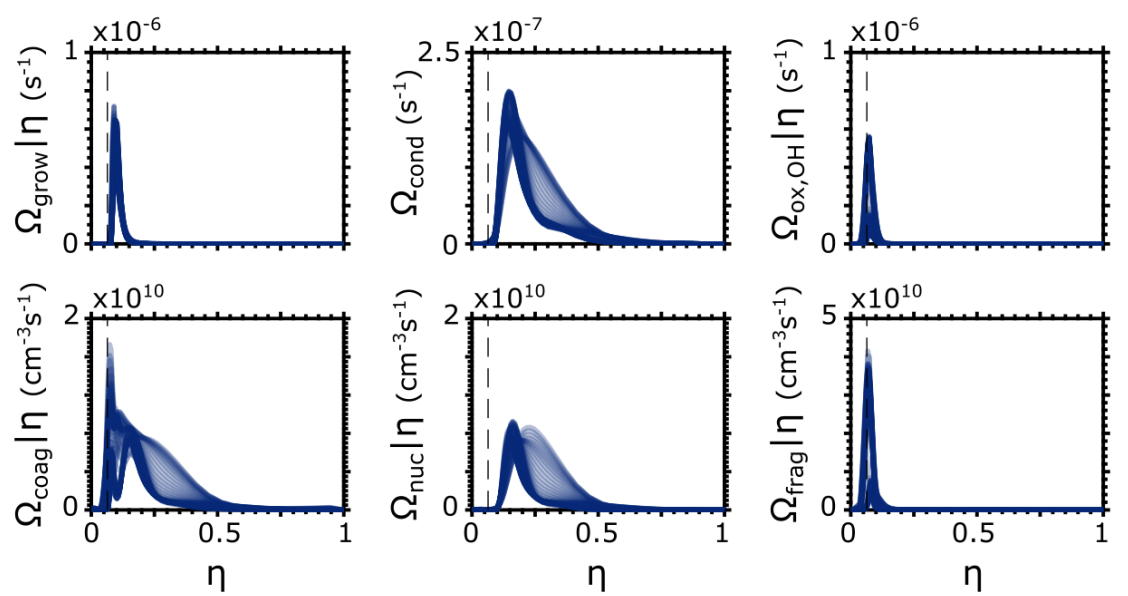

Figure 14: $\sum \dot{\Omega}_{j, s} \mid \eta$ of individual soot chemistry source terms in Eq. 3 at a location $(r=38$, $h=12 \mathrm{~mm}$ ) of case $A$ ( $0 \%$ dilution). Each line corresponds to a different time instant, uniformly sampled in a time period of $10 \mathrm{~ms}$. Dashed line: stoichiometry.

principally attributed to the penetration of dilution air in the primary region and the associated changes in residence time and local equivalence ratio. At the exit of the combustor, soot particles were found predominantly in the $1-10 \mathrm{~nm}$ size range and the predicted soot volume fraction (SVF) and the PSD agreed reasonably well with experiment for the case with dilution jets. However, the simulations predict too few and too small particles for the flame without air dilution.

This discrepancy may be due to an over-prediction of the oxidation kinetic rates in the soot model or a discrepancy in locating the soot in mixture fraction space due to the unity Lewis number $(L e=1)$ assumption used here in LESCMC. A comparison with the laminar flame data expressed in mixture fraction space offers some insights. An overall good agreement for soot precursors, such as PAH species, and SVF of the $L e=1$ LES-CMC against the laminar data (with $L e \neq 1$ ) partially justify the $L e=1$ assumption in the turbulent flame modelling. Nevertheless, a more prominent penetration of soot past the stoichiometric mixture fraction was evident in $\mathrm{CMC}$ compared to the laminar flame data, which may partly explain the suspected oxidation over-prediction. 
An analysis of the flame structure in mixture fraction space showed the hierarchy of reaction pathways during soot evolution, as predicted by the detailed approach employed here. The method can replicate the sensitivity of soot precursor evolution on scalar dissipation rate history and turbulent transport effects, which is essential for reliable predictions. The results suggest the codominance of acetylene-based surface growth and condensation via aromatics, but also the significant effects of oxidation-induced fragmentation in the studied conditions.

The results provide insights into the evolution of soot PSDs in highly recirculating flames. The LES-CMC approach coupled with a comprehensive sectional soot model offers a framework for further developments, including $L e \neq 1$ effects, quantitative comparison with in-flame PSD and SVF data, and more refined validation of the PAH predictions, once the exact nature of the laser-based techniques such as PAH-PLIF and LII are better understood.

\section{Acknowledgements}

The work presented in this paper was supported by the UK Engineering and Physical Sciences Research Council (EPSRC) and Rolls-Royce Group. The authors would like to thank I. El Helou, Dr A. Skiba and Dr G. De Falco for the useful discussions regarding the experiments and for providing the experimental data.

\section{Appendix A. Supplementary material}

The list of reactions for the gas-phase mechanism used in this work is available.

\section{Appendix B. Comparison with PAH-PLIF measurements}

Figure B1 shows a comparison of the predicted PAH species (taken as the sum of all aromatics from the detailed chemical scheme) against the experimentally observed PAH-PLIF mean signal. The key qualitative findings when 

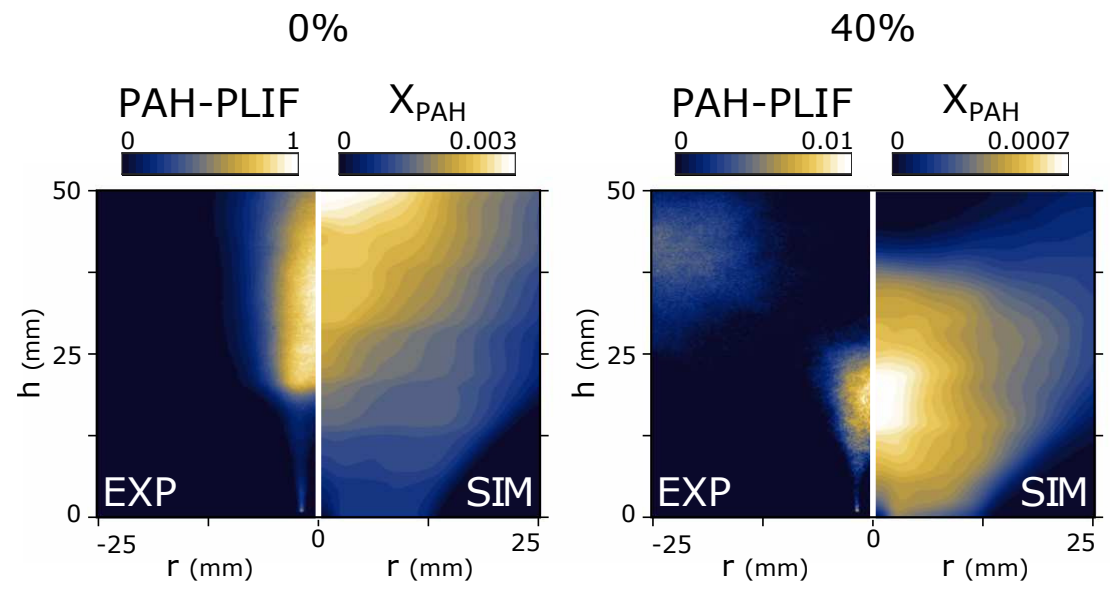

Figure B1: Comparison between experimentally obtained PAH-PLIF measurements (left-half plots) and sum of PAH mole fractions from the simulation (right-half plots). See Refs. 26, 27] for the experimental methodology.

comparing the two conditions are that for the no-dilution case: (i) the PAH's are found at larger concentrations; and (ii) the PAH regions are concentrated further downstream. Both these trends are reproduced by the simulation. The peak values between the two conditions are a factor of 100 smaller for the diluted case in the experiment, and by a factor of 5 in the simulations. Note that the comparison cannot be considered quantitative since the exact nature of PAH-PLIF measurements is not well understood (i.e., it is not fully known which species is being imaged). Nevertheless, the prediction of the basic trend that the diluted case has much fewer PAH's is reproduced properly. This suggests that the smaller amount of soot in this condition is due to the smaller amount of soot precursors, possibly due to the shorter residence times in the $\mathrm{PAH}$-producing mixture fractions and the quick disappearance of such mixture fractions due to the intense mixing.

\section{References}

口[1] A. D'Anna, Proc. Comb. Inst. 32 (1) (2009) 593-613. doi:10.1016/j. proci.2008.09.005 
[2] V. Raman, R. O. Fox, Annu. Rev. Fluid Mech. 48 (1) (2016) 159-190. doi:10.1146/annurev-fluid-122414-034306.

п [3] H. Wang, Proc. Comb. Inst. 33 (1) (2011) 41-67. doi:10.1016/j.proci. 2010.09 .009

[ [4] S. Rigopoulos, Prog. Energy Combust. Sci. 36 (4) (2010) 412-443. doi: $10.1016 / j \cdot$ pecs.2009.12.001.

n[5] S. Rigopoulos, Flow Turbul. Combust. 103 (3) (2019) 565-604. doi:10. 1007/s10494-019-00054-8.

[6] R. Santoro, H. Semerjian, R. Dobbins, Combust. Flame 51 (1983) 203-218. doi:10.1016/0010-2180(83)90099-8.

675 [7] M. Smooke, M. Long, B. Connelly, M. Colket, R. Hall, Combust. Flame 143 (4) (2005) 613-628. doi:10.1016/j.combustflame.2005.08.028

[8] N. Qamar, Z. Alwahabi, Q. Chan, G. Nathan, D. Roekaerts, K. King, Combust. Flame 156 (7) (2009) 1339-1347. doi:10.1016/j.combustflame. 2009.02 .011

[9] J. Zhang, C. R. Shaddix, R. W. Schefer, Rev. Sci. Instrum. 82 (7) (2011) 074101. doi:10.1063/1.3605491,

[10] M. E. Mueller, Q. N. Chan, N. H. Qamar, B. B. Dally, H. Pitsch, Z. T. 口 Alwahabi, G. J. Nathan, Combust. Flame 160 (7) (2013) 1298-1309. doi: 10.1016/j.combustflame.2013.02.010.

[11] M. E. Mueller, H. Pitsch, Phys. Fluids 25 (11) (2013) 110812. doi:10. 1063/1.4819347.

[12] K. P. Geigle, R. Hadef, W. Meier, J. Eng. Gas Turbines Power 136 (2) (2014) 021505. doi:10.1115/1.4025374.

[13] K. P. Geigle, R. Hadef, M. Stöhr, W. Meier, Proc. Comb. Inst. 36 (3) (2017) 3917-3924. doi:10.1016/j.proci.2016.09.024. 
[14] B. Franzelli, E. Riber, B. Cuenot, M. Ihme, ASME Turbo Expo, paper V04BT04A049, 2015. doi:10.1115/GT2015-43630.

[15] F. Dupoirieux, N. Bertier, C. Guin, K. Geigle, C. Eberle, P. Gerlinger, AerospaceLab (11) (2016) 20 p. hal-01368447.

[16] H. Koo, M. Hassanaly, V. Raman, M. E. Mueller, K. P. Geigle, J. Eng. Gas Turbines Power 139 (3) (2017) 031503. doi:10.1115/1.4034448

[17] S. T. Chong, M. Hassanaly, H. Koo, M. E. Mueller, V. Raman, K.-P. Geiq gle, Combust. Flame 192 (2018) 452-472. doi:10.1016/j . combustflame. 2018.02 .021

[18] S. T. Chong, V. Raman, M. E. Mueller, P. Selvaraj, H. G. Im, Proc. Comb. Inst. 37 (1) (2019) 1065 - 1074. doi:10.1016/j.proci.2018.06.093.

[19] B. Franzelli, A. Vié, N. Darabiha, Proc. Comb. Inst. 37 (4) (2019) 5411 5419. doi:10.1016/j.proci.2018.05.061

[20] C. Eberle, P. Gerlinger, K. P. Geigle, M. Aigner, Comb. Sci. and Tech. 187 (12) (2015) 1841-1866. doi:10.1080/00102202.2015.1065254.

[21] C. Eberle, P. Gerlinger, K. P. Geigle, M. Aigner, Comb. Sci. and Tech. 190 (7) (2018) 1194-1217. doi:10.1080/00102202.2018.1443444.

[22] F. Sewerin, S. Rigopoulos, Combust. Flame 189 (2018) 62-76. doi:10. $1016 / j$. combustflame.2017.09.045.

[23] P. Rodrigues, B. Franzelli, R. Vicquelin, O. Gicquel, N. Darabiha, Com-

1 bust. Flame 190 (2018) 477-499. doi:10.1016/j.combustflame.2017. 12.009

[24] M. Schiener, R. Lindstedt, Proc. Comb. Inst. 37 (1) (2019) 1049 - 1056. doi:10.1016/j.proci.2018.06.088

715 [25] T. E. Tracey, J. A. Sidey, E. Mastorakos, AIAA SciTech Forum, paper 1880, 2018. doi:10.2514/6.2018-1880 
[26] I. El Helou, A. Skiba, E. Mastorakos, J. A. Sidey, AIAA SciTech Forum, paper 1436, 2019. doi:10.2514/6.2019-1436.

[27] I. El Helou, A. Skiba, E. Mastorakos, in: MCS11, paper 157, Tenerife, Spain, 2019.

[28] G. De Falco, I. El Helou, P. M. de Oliveira, R. Yuan, A. D'Anna, E. Mastorakos, submitted to Proc. Comb. Inst. (2019).

[29] A. Attili, F. Bisetti, M. E. Mueller, H. Pitsch, Combust. Flame 161 (7) (2014) 1849-1865. doi:10.1016/j.combustflame.2014.01.008.

725 [30] A. Giusti, E. Mastorakos, C. Hassa, J. Heinze, E. Magens, M. Zedda, J. Eng. Gas Turbines Power 140 (6). doi:10.1115/1.4038025.

[31] A. Giusti, S. Gkantonas, J. M. Foale, E. Mastorakos, ASME Turbo Expo, paper V04BT04A032, 2018. doi:10.1115/GT2018-76705

[32] M. S. Anand, R. Eggels, M. Staufer, M. Zedda, J. Zhu, ASME Gas

730 - Turbine India Conference, paper V001T03A003, 2013. doi:10.1115/ GTINDIA2013-3537.

[33] A. Vreman, Phys. Fluids 16 (10) (2004) 3670-3681. doi:10.1063/1. 1785131

[34] H. Zhang, A. Garmory, D. E. Cavaliere, E. Mastorakos, Proc. Comb. Inst. 35 (2) (2015) 1167-1174. doi:10.1016/j.proci.2014.05.052.

[35] A. Garmory, E. Mastorakos, Proc. Comb. Inst. 35 (2) (2015) 1207-1214. doi:10.1016/j.proci.2014.05.032.

[36] A. Giusti, E. Mastorakos, Proc. Comb. Inst. 36 (2) (2017) 2625-2632. doi: 10.1016/j.proci.2016.06.035.

740 [37] E. E. O'Brien, T.-L. Jiang, Phys. Fluids 3 (12) (1991) 3121-3123. doi: $10.1063 / 1.858127$. 
[38] A. Garmory, E. Mastorakos, Proc. Comb. Inst. 33 (1) (2011) 1673 - 1680. doi:10.1016/j.proci.2010.06.065

[39] S. Navarro-Martinez, S. Rigopoulos, Flow Turbul. Combust. 89 (2) (2012) 311-328. doi:10.1007/s10494-011-9370-z.

[40] A. Kronenburg, R. W. Bilger, Phys. Fluids 9 (5) (1997) 1435-1447. doi: 10.1063/1.869256.

[41] A. Kronenburg, R. W. Bilger, J. H. Kent, Combust. Flame 121 (1) (2000) 24-40. doi:10.1016/S0010-2180(99)00146-7.

[42] J. C. Hewson, A. J. Ricks, S. R. Tieszen, A. R. Kerstein, R. O. Fox, Conditional-moment closure with differential diffusion for soot evolution in fire, Proceedings of the 2006 Summer Program-Center for Turbulence Research (2006) 311-323.

[43] D. O. Lignell, J. C. Hewson, J. H. Chen, Proc. Comb. Inst. 32 (1) (2009) 1491-1498. doi:10.1016/j.proci.2008.07.007.

[44] M.-C. Ma, C. B. Devaud, Combust. Flame 162 (1) (2015) 144-158. doi: $10.1016 / j$. combustflame.2014.07.008.

[45] D. O. Lignell, J. H. Chen, P. J. Smith, T. Lu, C. K. Law, Combust. Flame 151 (1-2) (2007) 2-28. doi:10.1016/j.combustflame.2007.05.013

[46] D. O. Lignell, J. H. Chen, P. J. Smith, Combust. Flame 155 (1-2) (2008) 316-333. doi:10.1016/j.combustflame.2008.05.020.

[47] F. Bisetti, G. Blanquart, M. E. Mueller, H. Pitsch, Combust. Flame 159 (1) (2012) 317-335. doi:10.1016/j.combustflame.2011.05.021.

[48] S. Gkantonas, A. Giusti, E. Mastorakos, in: ETMM12, Vol. paper 046F, Montpellier, France, 2018. doi:10.17863/CAM. 43222.

[49] C. Shaddix, T. Williams, Combustion Generated Fine Carbonaceous Particles, KIT Scientific Publishing, Karlsruhe, Germany (2009) 17-33. 
[50] R. J. Hall, Appl. Opt. 27 (5) (1988) 809-811.

[51] A. D'Anna, J. Kent, Combust. Flame 152 (4) (2008) 573-587. doi:10. $1016 / j$. combustflame. 2007.08 .003

[52] A. D’Anna, M. Sirignano, J. Kent, Combust. Flame 157 (11) (2010) 21062115. doi:10.1016/j.combustflame.2010.04.019.

[53] M. Sirignano, J. Kent, A. D’Anna, Combust. Flame 157 (6) (2010) 12111219. doi:10.1016/j.combustflame.2009.11.014

[54] M. Sirignano, J. Kent, A. D’Anna, Energy Fuels 27 (4) (2013) 2303-2315. doi:10.1021/ef400057r.

[55] A. D'Anna, M. Sirignano, in: Cleaner Combustion, Springer London, 2013, pp. 363-388. doi:10.1007/978-1-4471-5307-8_14.

[56] M. Sirignano, M. Alfè, A. Tregrossi, A. Ciajolo, A. D'Anna, Proc. Comb. Inst. 33 (1) (2011) 633 - 640. doi:10.1016/j.proci.2010.07.065

[57] M. Sirignano, A. Ciajolo, A. D'Anna, C. Russo, Combust. Flame 200 (2019) 23 - 31. doi:10.1016/j.combustflame.2018.11.006.

[58] A. D’Anna, M. Commodo, M. Sirignano, P. Minutolo, R. Pagliara, Proc. Comb. Inst. 32 (1) (2009) 793 - 801. doi:10.1016/j.proci.2008.06.200

[59] M. Sirignano, J. Kent, A. D’Anna, Proc. Comb. Inst. 35 (2) (2015) 1779 1786. doi:10.1016/j.proci.2014.05.010

[60] H. Michelsen, Proc. Comb. Inst. 36 (1) (2017) 717-735. doi:10.1016/j. proci.2016.08.027

[61] F. Schulz, M. Commodo, K. Kaiser, G. De Falco, P. Minutolo, G. Meyer, 790 D. Andrea, L. Gross, Proc. Comb. Inst. 37 (1) (2019) 885 - 892. doi: 10.1016/j.proci.2018.06.100. 
[62] M. Commodo, K. Kaiser, G. D. Falco, P. Minutolo, F. Schulz, A. D’Anna,

1. L. Gross, Combust. Flame 205 (2019) 154 - 164. doi:10.1016/j. combustflame.2019.03.042

[63] C. J. Pope, J. B. Howard, Aerosol Sci. Technol. 27 (1) (1997) 73-94. doi: $10.1080 / 02786829708965459$

[64] R. J. Santoro, T. T. Yeh, J. J. Horvath, H. G. Semerjian, Comb. Sci. and Tech. 53 (2-3) (1987) 89-115. doi:10.1080/00102208708947022.

[65] A. Veshkini, N. A. Eaves, S. B. Dworkin, M. J. Thomson, Combust. Flame 167 (2016) 335-352. doi:10.1016/j.combustflame.2016.02.024.

[66] S. B. Pope, New J. Phys. 6 (2004) 35-35. doi:10.1088/1367-2630/6/1/ 035 .

[67] J. H. Ferziger, M. Perić, Computational methods for fluid dynamics, Vol. 3, Springer, 2002.

[68] H. Jasak, H. Weller, A. Gosman, Int. J. Numer. Methods Fluids 31 (2) (1999) 431-449. doi:10.1002/(SICI) 1097-0363(19990930)31:2<431:: AID-FLD884>3.0.C0;2-T.

[69] G. Tabor, M. Baba-Ahmadi, Comput. Fluids 39 (4) (2010) 553-567. doi: $10.1016 / j . c o m p f l u i d .2009 .10 .007$

[70] L. Davidson, in: Advances and Applications in Fluid Mechanics, 2007, pp. $1-35$.

[71] F. Perini, E. Galligani, R. D. Reitz, Energy Fuels 26 (8) (2012) 4804-4822. doi:10.1021/ef300747n.

[72] S. Chowdhury, W. R. Boyette, W. L. Roberts, J. Aerosol Sci. 106 (2017) 56-67. doi:10.1016/j.jaerosci.2016.10.012.

[73] W. Boyette, S. Chowdhury, W. Roberts, Flow Turbul. Combust. 98 (4) (2017) 1173-1186. doi:10.1007/s10494-017-9802-5. 
[74] M. Lucchesi, A. Abdelgadir, A. Attili, F. Bisetti, Combust. Flame 178 (2017) 35-45. doi:10.1016/j.combustflame.2017.01.002

[75] Y. Wang, S. H. Chung, Prog. Energy Combust. Sci. 74 (2019) 152-238. doi:10.1016/j.pecs.2019.05.003

[76] R. Lindstedt, S. Louloudi, Proc. Comb. Inst. 30 (1) (2005) 775 - 783. doi:10.1016/j.proci.2004.08.080 